\title{
National Ignition Facility Project Execution Plan
}

\author{
August 1997
}
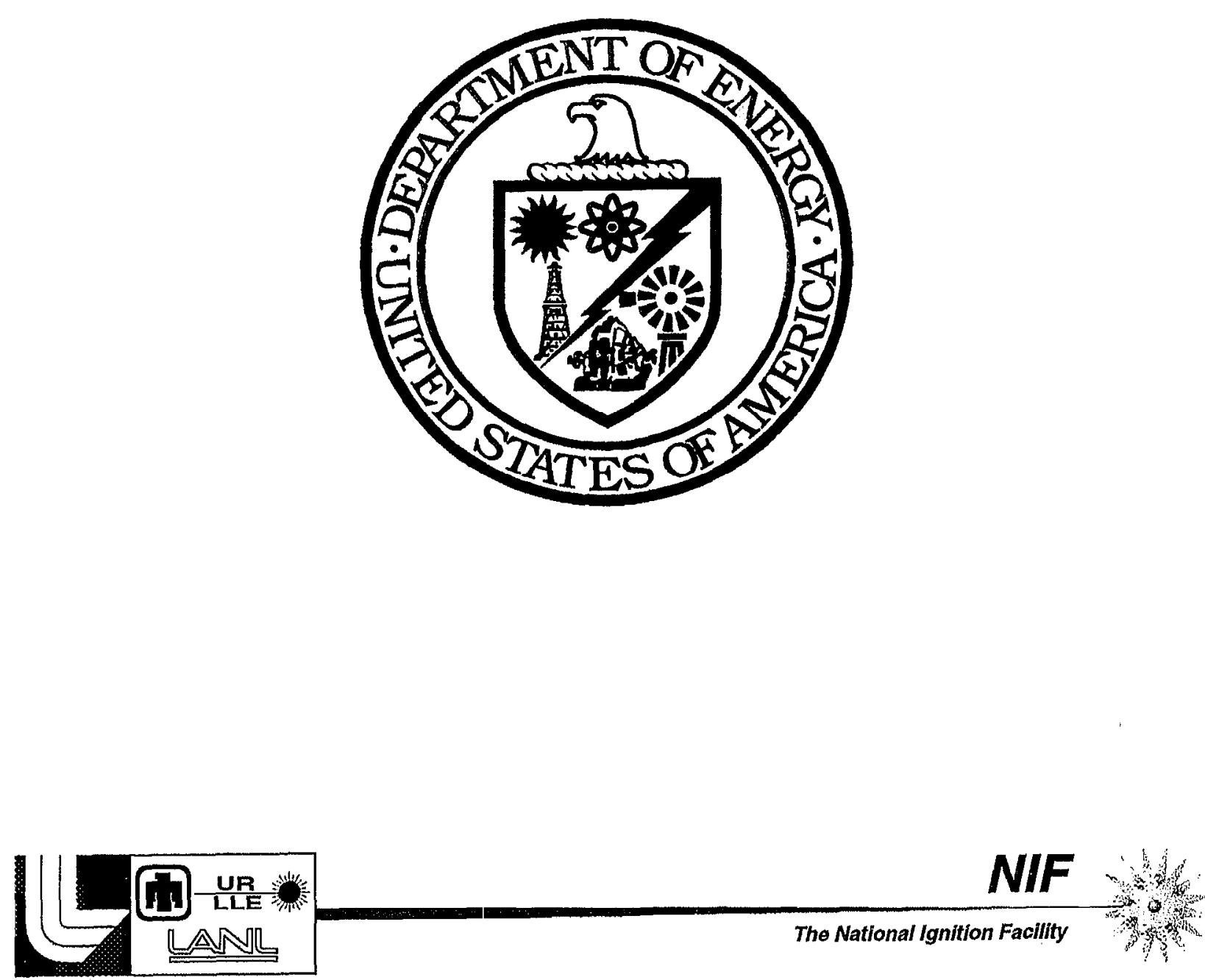


\section{DISCLAIMER}

This document was prepared as an account of work sponsored by an agency of the United States Government. Neither the United States Government nor the University of California nor any of their employees, makes any warranty, express or implied, or assumes any legal liability or responsibility for the accuracy, completeness, or usefulness of any information, apparatus, product, or process disclosed, or represents that its use would not infringe privately owned rights. Reference herein to any specific commercial product, process, or service by trade name, trademark, manufacturer, or otherwise, does not necessarily constitute or imply its endorsement, recommendation, or favoring by the United States Government or the University of California. The views and opinions of authors expressed herein do not necessarily state or reflect those of the United States Government or the University of California, and shall not be used for advertising or product endorsement purposes.

This report has been reproduced directly from the best available copy.

Available to DOE and DOE contractors from the Office of Scientific and Technical Information

P.O. Box 62, Oak Ridge, TN 37831

Prices available from (615) 576-8401, FTS 626-8401

Available to the public from the

National Technical Information Service

U.S. Department of Commerce

5285 Port Royal Rd.,

Springfield, VA 22161 


\title{
National Ignition Facility Project Execution Plan
}

\author{
August 1997
}

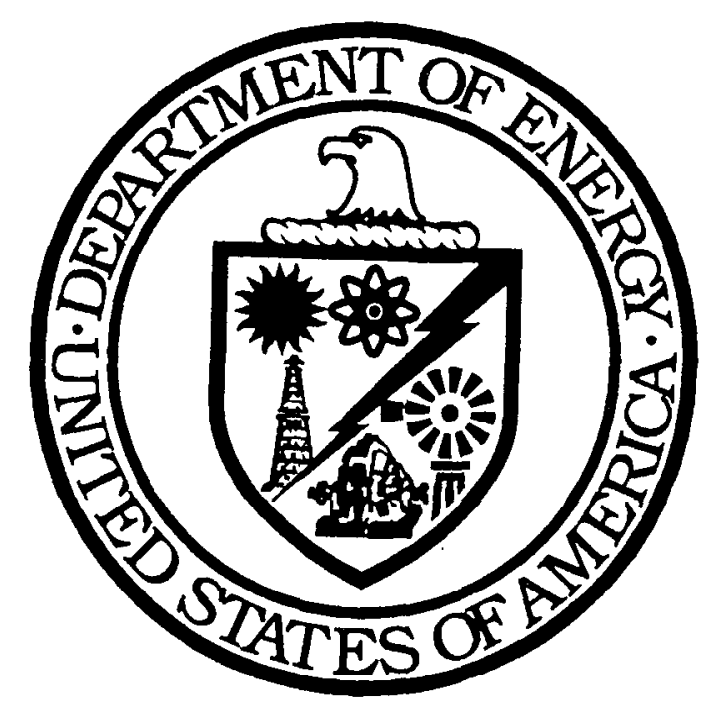

Copy \#

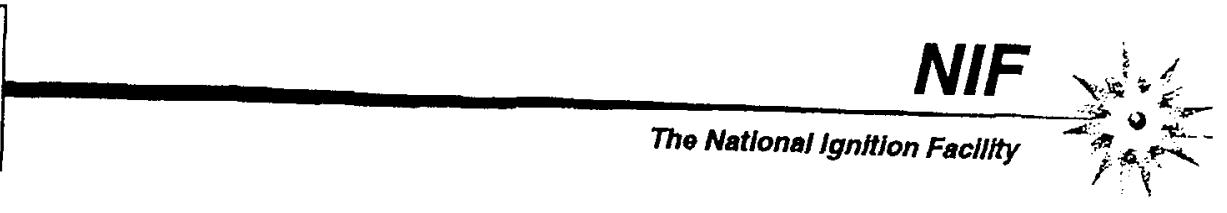




\title{
National Ignition Facility
}

\section{Project Execution Plan}

\author{
Revision 1
}
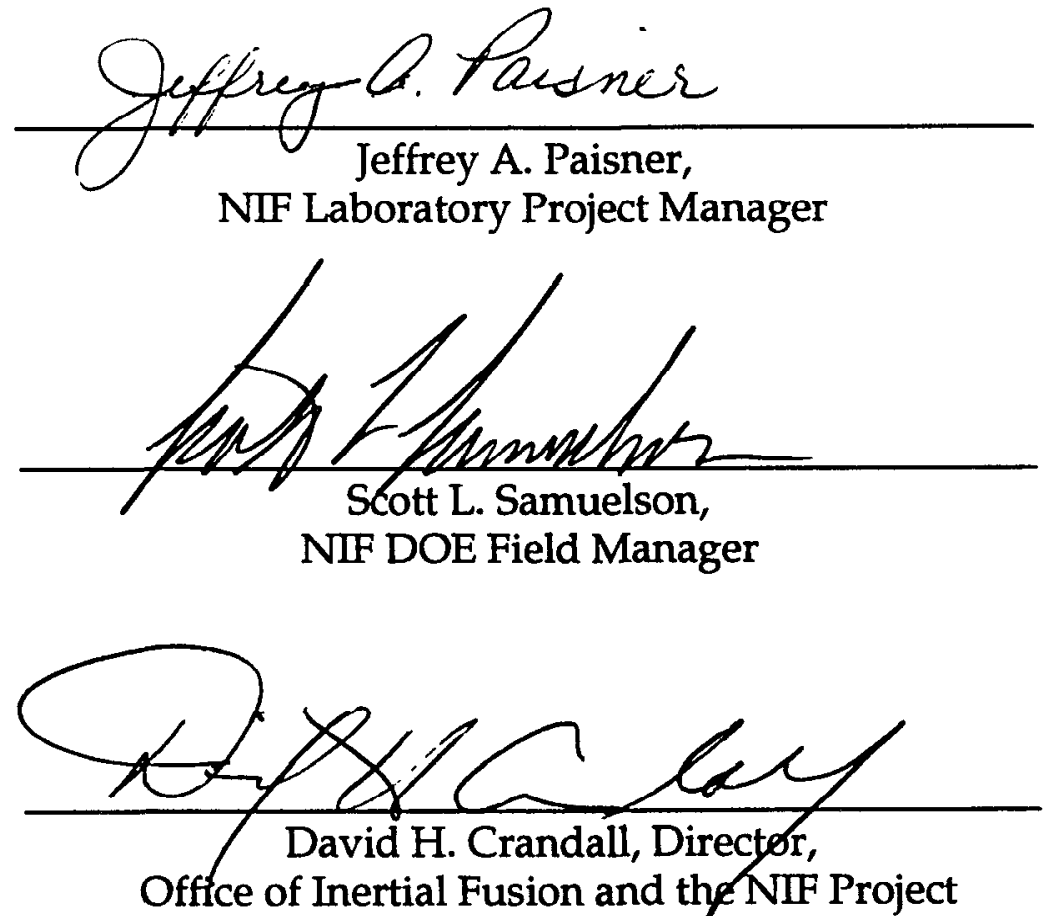


\section{Contents}

1. Justification of Mission Need........................................................................ 1

2. Project Description .......................................................................................... 3

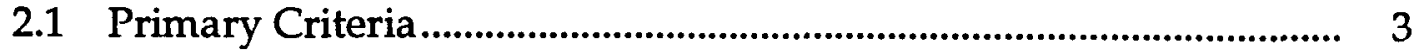

2.2 NIF Summary Design Description...................................................... 5

2.3 Work Breakdown Structure .............................................................. 9

3. Management Roles and Responsibilities........................................................... 10

3.1 DOE-HQ................................................................................................. 11

3.1.1 Director, Office of Inertial Fusion and the

National Ignition Facility ...................................................... 12

3.2 DOE Field Office.......................................................................... 13

3.2.1 NIF DOE Field Manager ...................................................... 13

3.3 Laboratory Lasers Directorate.................................................................. 14

3.4 NIF Laboratory Project Office............................................................... 15

3.4.1 NIF Laboratory Project Manager......................................... 15

3.4.2 NIF Deputy Project Managers................................................. 16

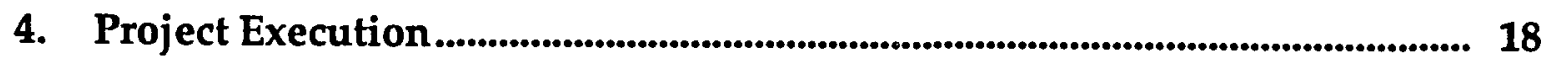

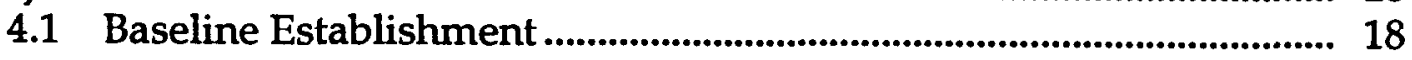

4.1.1 Technical Baseline ................................................................. 18

4.1.2 Cost Baseline ......................................................................... 18

4.1.3 Schedule Baseline.................................................................... 20

4.2 Baseline Change and Contingency Control....................................... 20

4.2.1 Baseline Change Control and Configuration Control ....... 20

4.2.2 Contingency Control ............................................................ 23

4.3 DOE Budget Authorization Process ....................................................... 24

4.4 Procurement and Contracting ........................................................... 24

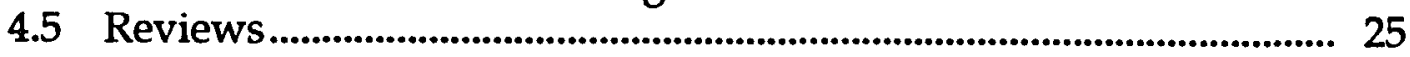

4.5.1 DOE Status Reviews ........................................................... 25

4.5.2 Independent Reviews......................................................... 25

4.6 Performance Control and Reporting Systems..................................... 25

4.6.1 Control Systems....................................................................... 26

4.6.2 Reporting.............................................................................. 26

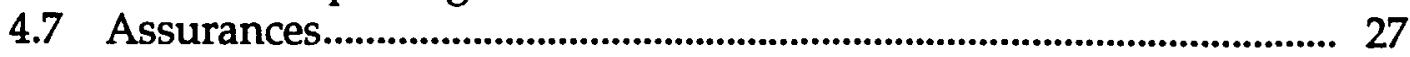

4.7.1 Quality Assurance.................................................................. 27

4.7.2 Risk and Graded Approach................................................. 28

5. Method of Accomplishment ......................................................................... 29

5.1 Environment, Safety, and Health Planning......................................... 29

5.1.1 NEPA Determination and Site Selection ............................ 29

5.1.2 Safety Documents........................................................................ 30 
5.2 NIF Design................................................................................................ 30

5.2.1 Conceptual and Advanced Conceptual Design.................. 31

5.2.2 Title I, II, and III Design ...................................................... 32

5.3 Construction and Equipment Procurement and Installation............. 32

5.4 Operational Testing and Start-up.............................................................. 33

5.5 Project Completion ................................................................................... 33

5.6 Security.................................................................................................... 34

6. Effective Date and Amendments .............................................................................. 35

7. References and Notes ................................................................................................. 36

\section{Appendices}

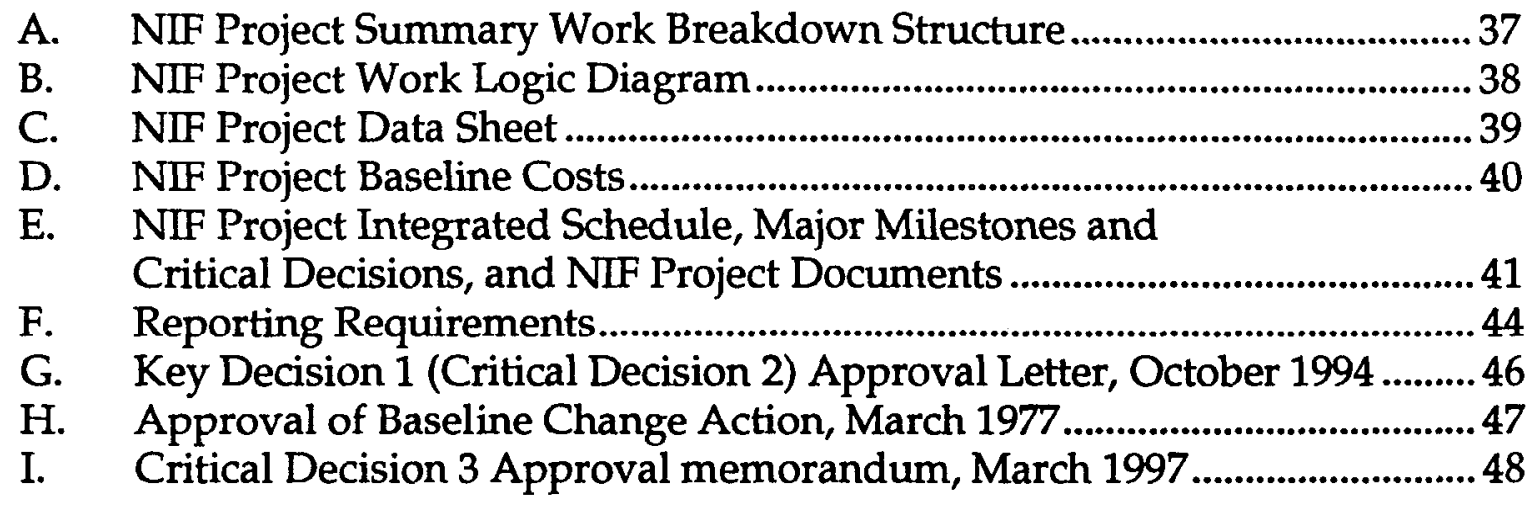

Figures

2-1. NIF Laser and Target Area Building................................................................. 6

2-2. NIF Target Chamber......................................................................................... 7

2-3. Indirect- and Direct-Drive Target Ignition...................................................... 8

3-1. NIF Project Management Structure..................................................................... 11

4-1. Relational Hierarchy of Criteria ......................................................................... 19

4-2. Baseline Change Control Board (BCCB) Hierarchy........................................ 21

A-1. NIF Project Summary Work Breakdown Structure....................................... 37

B-2. NIF Project Work Logic Diagram..................................................................... 38

E-1. NIF Summary Integrated Project Schedule....................................................... 41

\section{Tables}

4-1. Baseline Change Control Levels ......................................................................... 22

4-2. NIF Project Status Reviews................................................................................. 25

E-1. NIF Project Major Milestones and Critical Decision Points......................... 42

E-2. NIF Project Documents......................................................................................... 43

F-1. Project Reporting Requirements...................................................................... 45 


\section{Justification of Mission Need}

The National Ignition Facility Justification of Mission Need, 1 which was approved by the Secretary of Energy in January 1993, defines the mission of the National Inertial Confinement Fusion Program and discusses the specific mission of the National Ignition Facility (NIF) Project. The most immediate application of the NIF will be to provide nuclear-weapon-related physics data, because many high-energy-density physics phenomena that will occur during NIF experiments are relevant and similar to those occurring in nuclear weapons. With the comprehensive test ban now signed by the President and awaiting ratification by the Senate, the NIF will provide an important capability for weapons-physics simulations. Along with numerical simulations and other aboveground experimental facilities, the NIF will provide critical data that will allow the United States to maintain its technical capabilities in nuclear weapons in the absence of underground testing. As a secondary objective specified by the National Energy Strategy, the NIF will advance our understanding of inertial confinement fusion and help to assess its potential as an energy source. Achieving fusion ignition in the NIF will advance both defense and energy objectives. In affirming the project's Critical Decision 2, Approval of New Start, ${ }^{2}$ the Secretary of Energy verified the mission need and emphasized that the NIF has the potential to contribute significantly to the following Department of Energy (DOE) mission areas:

\section{Stockpile stewardship}

In the absence of underground nuclear tests, the NIF will be a critical tool for the Department's science-based Stockpile Steward1 ${ }^{1}$ ship and Management Program. It will help to maintain the continued reliability and effectiveness of the stockpile by creating experimental conditions that approach certain aspects of nuclear-weapons physics. In particular, the NIF's experimental capability will allow nuclear-weapons scientists to assess stockpile problems, verify computational tools, test for nuclear-weapons effects, and increase their understanding of weapons physics.

\section{Inertial fusion energy}

The NIF will represent the scientific culmination of more than 30 years of inertial confinement fusion research. In inertial confinement fusion, laser beams or particle beams are focused on spherical targets containing fusion fuel, causing them to implode, creating the high temperatures and pressures necessary for these targets to burn. With the NIF, scientists plan to achieve ignition (self-heating of the fuel) and energy gain (more fusion energy produced than laser energy deposited) in the laboratory for the

\footnotetext{
- Although Key Decisions 0 and 1 have already occurred, the Key Decision process is being phased out and a Critical Decision process is being implemented. The correlations between Key Decisions and Critical Decisions are: Key Decision $0=$ Critical Decision 1 (Approval of Mission Need); Key Decision $1=$ Critical Decision 2 (Approval of New Start); Key Decision 2 (Start Final Design) is no longer used and has no Critical Decision equivalent; Key Decision 3 = Critical Decision 3 (Start Construction); and Key

Decision 4 = Critical Decision 4 (Project Completion).
} 
first time. As envisioned, inertial fusion energy power plants will use high-repetitionrate laser or ion drivers (about ten pulses per second). Heat from continual fusion reactions will be absorbed by coolants surrounding fuel pellets and converted to electricity. The NIF will provide critical data on the design requirements of these drivers and on other critical components. This data will also be used to help design an Engineering Test Facility that is conceived for early in the next century as the next step toward a functional inertial fusion energy power plant.

\section{Science, technology, and other applications}

The NIF will attract world-class scientists and engineers to work on science of national importance. The ability to probe experimental conditions similar to those at the center of the Sun and the stars would accelerate progress in basic sciences such as stellar physics and cosmology. In addition, as the world's largest precision optical instrument, the project would spur industrial capabilities, technologies, and commercial applications. 


\section{Project Description}

Description and participants-The NIF Project is a DOE Strategic System. The Project provides the design, equipment procurement, construction, and acceptance testing of the NIF experimental and support facilities. The Project involves DOE and the following DOE laboratories and contractors within the National Inertial Confinement Fusion Program:

- Lawrence Livermore National Laboratory.

- Los Alamos National Laboratory.

- Sandia National Laboratories.

- University of Rochester Laboratory for Laser Energetics.

Cost and timeline-The approval of Key Decision 1, now known as Critical Decision 2, in October 1994 originally established the Project as a fiscal year 1996 line item with a total estimated cost of $\$ 842.6$ million and a total project cost of $\$ 1074$ million, with completion (Critical Decision 4) scheduled for fiscal year 2002. The current cost and schedule basis is described in the NIF Project Data Sheet in Appendix C. In addition to the mandatory Critical Decisions, a Key Decision 1' was introduced to assess the NIF's potential effect on the nonproliferation of nuclear weapons. This process, which included public review, culminated in a DOE report and decision by the Secretary of Energy in December 1995 on the NIF's role in promoting U.S. goals of nuclear nonproliferation. The NIF will be subject to applicable safety and health, environmental, security, and quality assurance requirements.

Selected site and criteria-The Record of Decision for the Stockpile Stewardship and Management Programmatic Environmental Impact Statement (SSMPEIS) issued in December 1996 by the Secretary of Energy specified Lawrence Livermore National Laboratory as the selected site. Other candidate sites were Los Alamos National Laboratory, Sandia National Laboratories-New Mexico, and the Nevada Test Site. The initial site-selection criteria state that the selected site should:

1. Be a DOE-Defense Programs controlled federal site.

2. Have a significant inertial confinement fusion infrastructure.

3. Provide adequate protection of the public and the environment.

4. Have hazardous and radioactive waste-management capability.

5. Have adequate transportation services (e.g., transport of targets).

\subsection{Primary Criteria}

The National Ignition Facility Functional Requirements and Primary Criteria ${ }^{3}$ represents the top-level system requirements that must be achieved to support the National Ignition Facility Justification of Mission Need ${ }^{1}$ and to ensure that the construction and operation 
meet applicable federal, state, and local requirements to ensure protection of workers, the public, and the environment. These criteria also address the project assurance requirements (e.g., Security, Quality Assurance). The primary criteria are approved by the DOE's Director, Office of the Inertial Fusion and the NIF Project, and become one basis for the NIF Technical Baseline. All proposed changes to the approved primary criteria are subject to review and approval by the Level 1 Baseline Change Control Board, chaired by the Director. The performance requirements and the principal primary criteria for NIF systems are listed in the following sections.

\section{Performance requirements}

The primary NIF performance requirements include the following:

- Each beam shall deliver its design energy and power encircled in a $600-\mu \mathrm{m}$ laser spot size at the target plane with spatial and temporal beam conditioning to control intensity fluctuations.

- Symmetrical implosion of the capsule (hydrodynamics) using two-sided target irradiation geometry, with two cones of beams per side, and eightfold rotation symmetry. The beams will be pointed on target to within $50 \mu \mathrm{m} \mathrm{rms}$.

- A carefully shaped laser temporal pulse, with a maximum peak-to-foot contrast ratio of 50:1.

- Sufficient energy in the pulse to give a high probability of ignition. The laser will routinely deliver $500 \mathrm{TW} / 1.8 \mathrm{MJ}$ at $3 \omega$ to the laser entrance hole of the target hohlraum.

- Design life for permanent structures of at least 30 years.

Laser Criteria

\begin{tabular}{lcc}
\hline & Baseline & Enhanced Envelope* \\
\hline \hline - & $\begin{array}{c}1.8 \mathrm{M} \text { ) (measured incident on a } \\
\text { hohlraum entrance hole) }\end{array}$ & Same \\
- Peak power & $500 \mathrm{TW}$ & Same \\
- Power balance (over any $2 \mathrm{~ns})$ & $<8 \% \mathrm{rms}$, Indirect Drive & Direct Drive \\
- Wavelength & $0.35 \mu \mathrm{m}$ & Same \\
- Pointing & less than $50 \mu \mathrm{m}$ rms & Same \\
(beam centroid deviation) & & \\
\hline The NIF baseline criteria employs the indirect-drive approach as described in the NIF Conceptual Design Report. \\
$\begin{array}{l}\text { Indirect drive is currently emphasized in inertial confinement fusion research and planned for the NIF experimental } \\
\text { program. However, an enhanced option that includes capability for future full implementation of direct drive in }\end{array}$ \\
$\begin{array}{l}\text { addition to indirect drive is included. This enhanced option could provide the capability to perform an increased } \\
\text { number of experiments (both yield and no yield) to accommodate greater user needs. }\end{array}$
\end{tabular}


Experimental Area and Target Chamber Criteria

\begin{tabular}{lcc}
\hline & Baseline & Enhanced Envelope* \\
\hline - Supports experimenter-supplied & Yes & Yes \\
cryostats for cryogenic targets & & Yes \\
- Supports classified experiments & $1200 \mathrm{MJ} / \mathrm{yr}$ & Same \\
- Maximum annual fusion yield & $45 \mathrm{MJ}\left(1.6 \times 10^{19}\right.$ neutrons) & Same \\
- Maximum credible D-T fusion & & \\
\hline $\begin{array}{l}\text { yield limit } \\
\text { option provides the future capability to perform an increased number of experiments (both yield and no yield) to } \\
\text { accommodate greater user needs. }\end{array}$
\end{tabular}

\section{Assurance Criteria}

The NIF must meet the following assurance criteria:

- Hazards category: low hazard, radiological.

- Public dose will remain below $100 \mathrm{mrem} / \mathrm{y}$ from all exposure modes and $10 \mathrm{mrem} / \mathrm{y}$ from emissions of radionuclides in ambient air.

- The NIF will meet the requirements for an improved risk level of fire protection sufficient to meet DOE objectives.

- Waste management shall minimize the generation of waste at the source per applicable DOE orders.

- NIF safeguards and security will physically protect and control classified data and equipment. The NIF is not classified as a vital facility.

\subsection{NIF Summary Design Description}

The NIF will be an experimental fusion facility that includes a laser and a target area. The laser will be capable of providing an output pulse with the required energy of $1.8 \mathrm{MJ}$ and an output pulse power of $500 \mathrm{TW}$ at a wavelength of $0.35 \mu \mathrm{m}$ with specified symmetry, beam balance, and pulse shape. Figure 2-1 shows the NIF experimental facility, which will house a multibeam, neodymium-doped glass laser capable of generating and delivering the pulses to a target chamber. In the 10-m-diameter shielded target chamber, the light from the NIF beams will be tightly focused into a cmsize target hohlraum with a 2-mm-diameter capsule inside (see Figure 2-2) containing deuterium and tritium fusion fuel (indirect drive). The laser light will compress and heat the fuel to produce fusion reactions yielding up to 10 times the laser energy delivered to the target. 


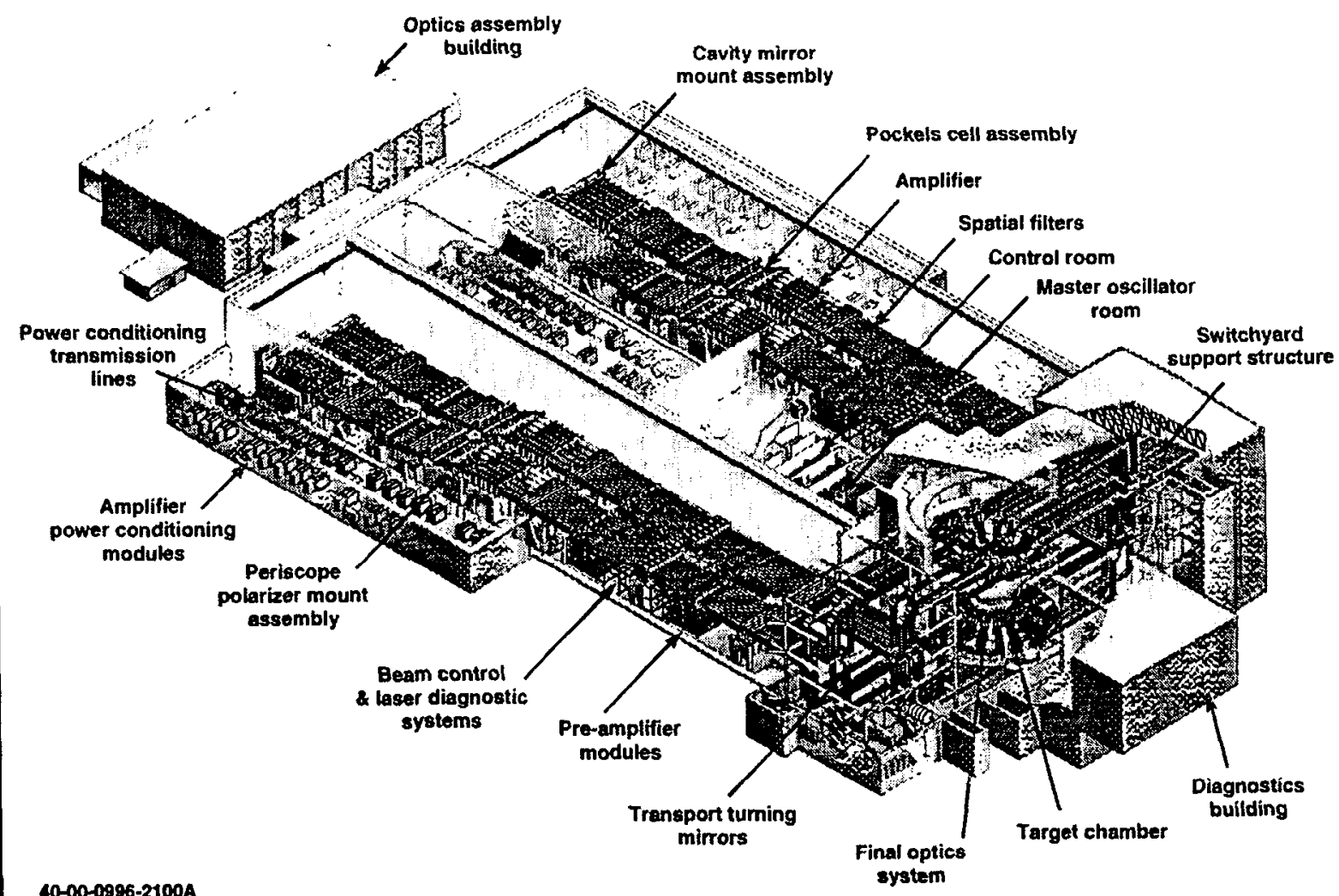

Figure 2-1. NIF Laser and Target Area Building.

The sequence of events that occur in indirect- and direct-drive target ignition are shown in Figure 2-3. This sequence, when the fusion capsule ignites, leads to the creation of a miniature star, which will exist for less than a billionth of a second. Diagnostics will be used to make the accurate measurements of the high temperature and pressure states of matter. The recorded data will be used by researchers involved in national security, energy, and basic science research.

The NIF will consist of the following four primary systems, which are described in the following paragraphs:

1. Laser System and Optical Components.

2. Target Area.

3. Laser and Target Area Building.

4. Integrated Computer Control System. 


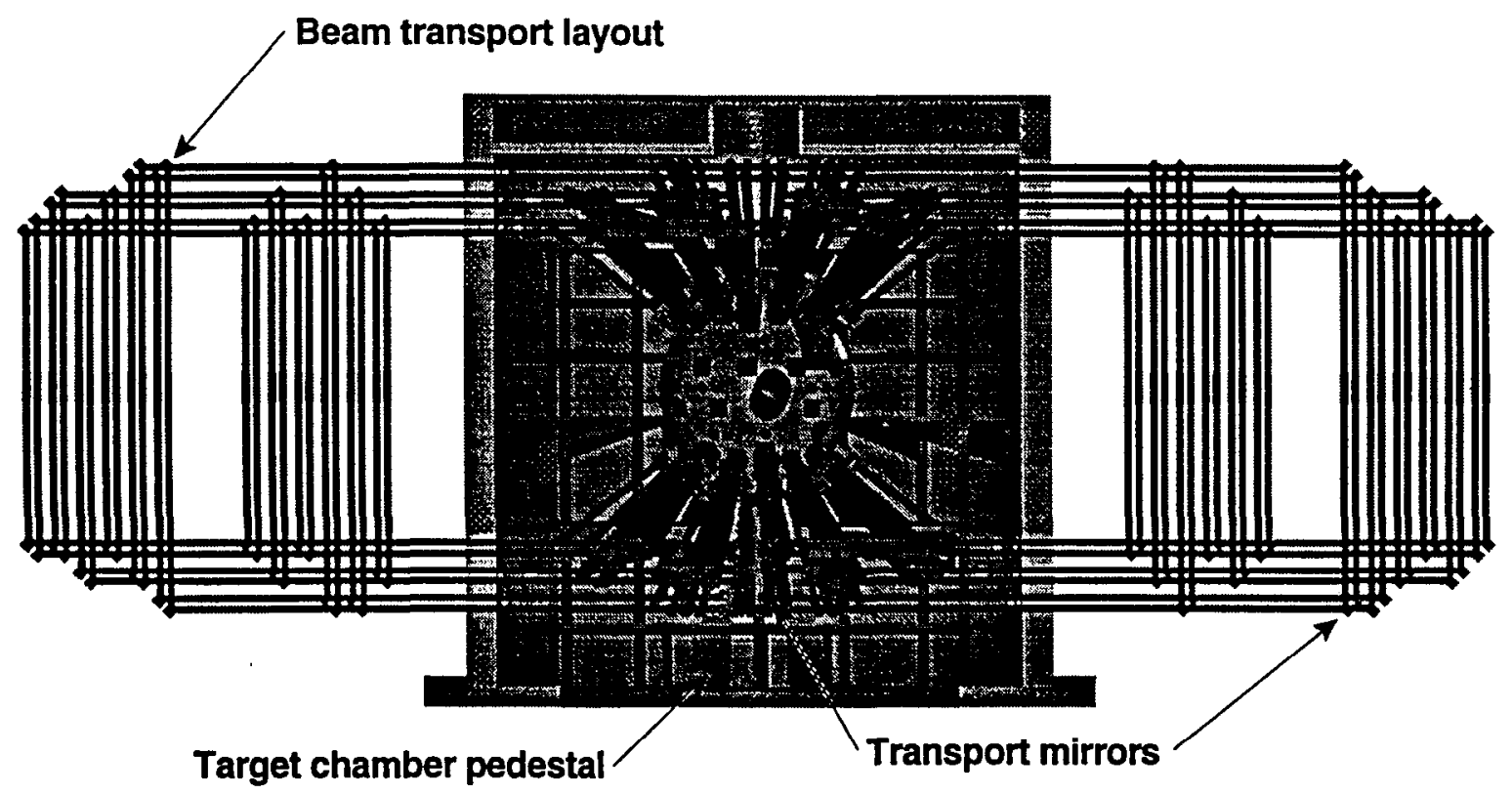

40-00-0796-1623Bpb01

107/96SAK

Figure 2-2. NIF Target Chamber.

Laser System and Optical Components-The NIF laser system will consist of 192 laser beamlets configured to illuminate the target surface with a specified symmetry, uniformity, and temporal pulse shape. The laser pulse will originate in the pulse generation system. This precisely formatted, low-energy pulse will be amplified in the main amplifier. To minimize intensity fluctuations, each beam will pass through a pinhole in a spatial filter on each of the four passes through the amplifier and through a transport spatial filter.

The beam transport will direct each high-power laser beam to an array of ports distributed around the target chamber, where the frequency of the laser light will be tripled in frequency (to $0.35 \mu \mathrm{m}$ ), spatially modulated (by phase plates), and focused on the target. Systems will automatically control the alignment and the measurement of the power and energy of the beam. Structural support and auxiliary systems will provide the stable platform and utilities required.

Target Area-The target area will include the 10-m-diameter, low-activation aluminum alloy vacuum chamber located in the heavily shielded target area of the Laser and Target Area Building. A target positioner will precisely locate the fusion targets in the target chamber. The target chamber and the building structure will provide the primary and secondary confinement of radioactivity (e.g., $x$-rays, neutrons, tritium, and activation products). Diagnostics arranged around the target chamber will obtain the 


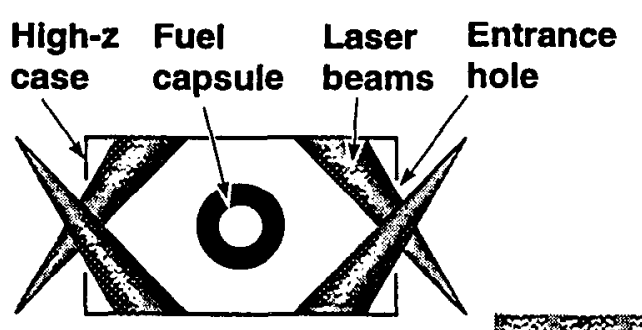

Indirect drive

$X$-rays rapidly heat the surface of the fuel capsule.

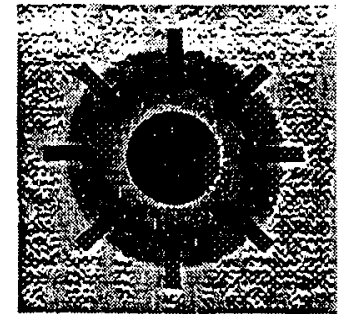

Direct drive

Laser beams rapidly heat the surface of the fuel capsule.

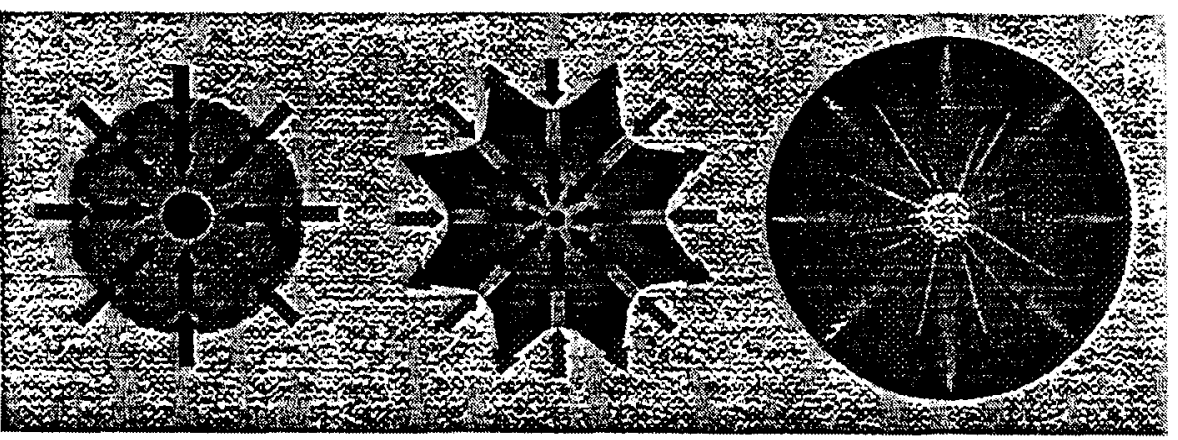

Capsule compression

Fuel is compressed by the rocket-like blowoff of the hot surface materlal.
Ignition

During the final part of the implosion, the fuel core reaches 20 times the density of lead and ignites at $100,000,000^{\circ} \mathrm{C}$.
Burn

Thermonuclear burn spreads rapidly through the compressed fuel, yielding many times the input energy.

05-00-0784-2897pb01

Figure 2-3. Indirect- and Direct-Drive Target Ignition.

comprehensive test data. Structural, utility, and other systems will provide all required operation and maintenance (e.g., decontamination of components) support.

Laser and Target Area Building-The Laser and Target Area Building (shown in Figure 2-1) provides the environmentally and vibration-controlled facility to house the NIF experimental systems. It will be a reinforced-concrete and structural steel building with a footprint of approximately $20,300 \mathrm{~m}^{2}$. The building will include two laser bays, each approximately $31 \mathrm{~m}$ wide by $135 \mathrm{~m}$ long joined at a central target area, which is a shielded (1.8-m-thick concrete) cylinder approximately $32 \mathrm{~m}$ in diameter and about 32 $\mathrm{m}$ high. The target chamber will be structurally supported in this cylinder. The Laser and Target Area Building will include security systems, radioactive confinement and shielding, control rooms, supporting utilities, fire protection, monitoring, and decontamination and waste handling. 
Optics Assembly Building-This building has a footprint of $2600 \mathrm{~m}^{2}$ and provides about 1400 square meters of clean room area for large optics assembly, mechanical cleaning, and optics and mechanical transfer. The Optics Assembly Building is connected to the Laser and Target Area Building via a "clean corridor."

Integrated Computer Control System-The integrated computer control system will contain the computer system required to control the laser and target systems. The system will include the hardware and software necessary to support NIF operations, including the integrated timing system for experimental control of laser and diagnostic operations, data acquisition, safety interlocks, and area access control.

NIF Operations-Facility operations will be supported by a site infrastructure that will provide the utilities, auxiliary systems, and personnel support. The onsite support facilities, which are available at the LLNL, include the following:

- Utilities.

- Offices for onsite and offsite technical personnel (e.g., visiting scientists)

- Laser and optics laboratories.

- Target receiving, inspection, storage, and repair.

- Optics component and system assembly and maintenance.

- Warehousing.

- Mechanical and electrical shops.

- Site emergency services.

- Safeguards and security systems.

- Classified and unclassified computer systems.

- Library.

- Cafeteria.

The onsite support includes a body of scientific, engineering, and operations personnel experienced in inertial confinement fusion and the construction and operation of large laser systems.

\subsection{Work Breakdown Structure}

The NIF Project Work Breakdown Structure is the organizing element for the NIF Project. It serves as the top-level element for all subsequent work breakdown structure elements, and consists of capital-funded Total Estimated Cost and operating-funded Other Project Cost activities. Appendix A includes the NIF Project Summary Work Breakdown Structure down to Level 3 elements. 


\section{Management Roles and Responsibilities}

Overall DOE management responsibilities were first stated in the approved Project Charter ${ }^{4}$ signed in March 1993. Since then, the DOE's Office of the National Ignition Facility was established to interpret, explain, and defend the role of the NIF Project and provide executive-level project control for the DOE. More recently part of the DOE's Office of Research and Inertial Fusion has been combined with the Office of the National Ignition Facility under a single director. It is now called the Office of Inertial Fusion and the NIF Project.

Section 3.1 discusses these relationships. Section 3.2 outlines the role of the NIF DOE Field Office. Section 3.3 describes the participant's responsibilities and interfaces.

Successful completion of the NIF Project requires a team effort with clear definition of roles, responsibilities, interfaces, and open communications among all participants. The key management positions are:

1. Director, Office of Inertial Fusion and the NIF Project-responsible for the DOE-HQ roles for formulating policy, budget authorization; responsible for ensuring that National Inertial Confinement Fusion Program goals are achieved and the technology basis required for the NIF is developed; and overall project direction.

2. NIF DOE Field Manager-responsible for the formal day-to-day onsite management oversight; cost and schedule control; and environment, safety, and health requirements.

3. NIF Laboratory Project Manager-responsible for implementing the project and directing the participating laboratories and other contractors (such as architect/engineers, construction manager, and engineering support).

4. Laboratory Deputy Project Managers-responsible for supporting the NIF Laboratory Project Manager in the project implementation while representing their institution.

All participants will work together in a manner that will foster teamwork and performance excellence through a system of continuous interaction, review, and feedback. Although a formal communication path will be established, frequent informal communications are encouraged to develop an effective basis for project decisions. Headquarters, Field, and Laboratory are expected to communicate extensively. For most major issues, it is assumed that the Project Leadership Team-the Director, Office of Inertial Fusion and the NIF Project; the NIF DOE Field Manager; and the NIF Laboratory Project Manager-will routinely and effectively communicate with each other and with other pertinent project participants. Figure 3-1 depicts the formal NIF project management structure for the primary participants. 


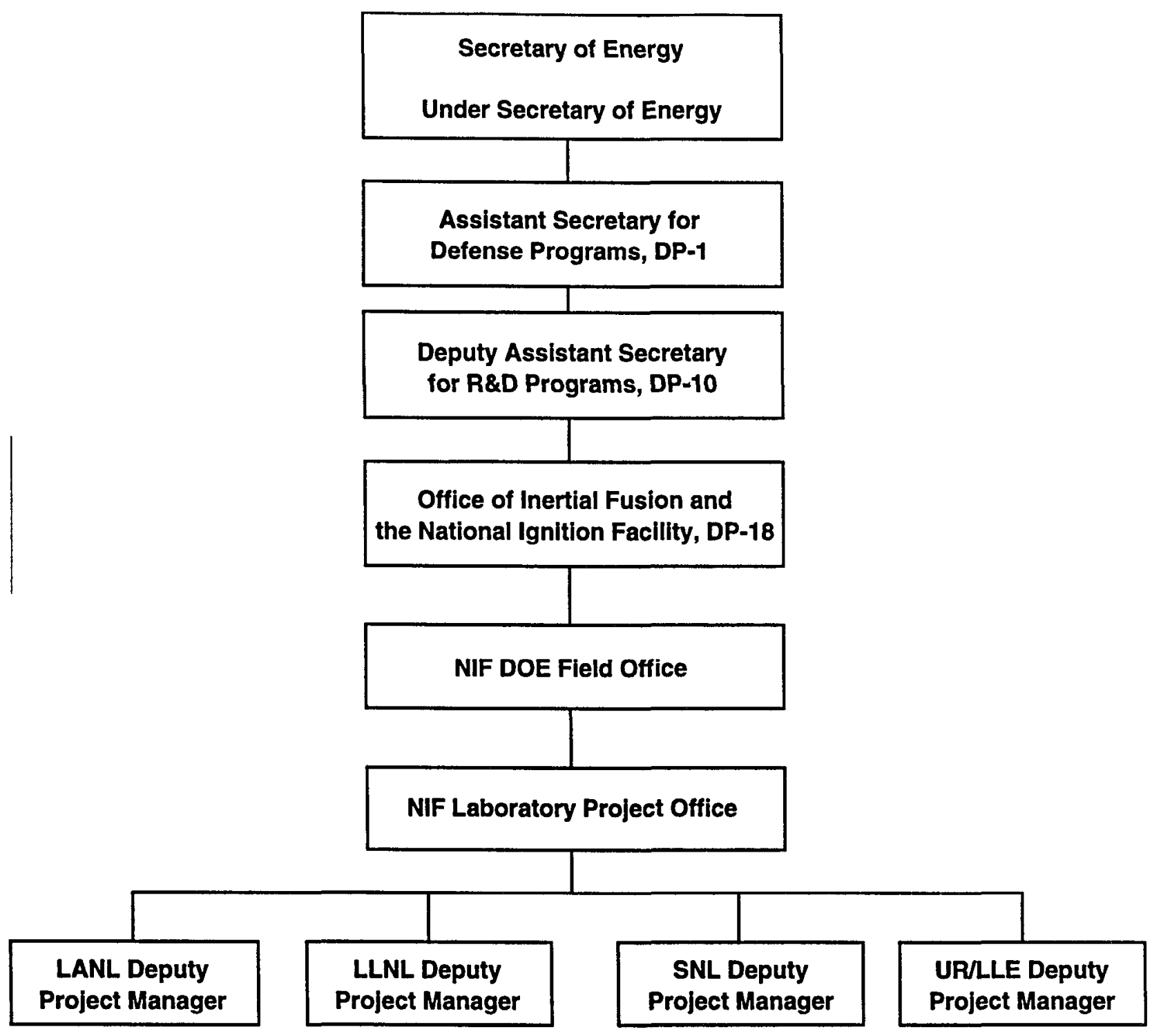

40-00-0494-1621pb02

Figure 3-1. NIF Project Management Structure.

\subsection{DOE-HQ}

The Secretary of Energy is the Acquisition Executive for the NIF Project. All Critical Decisions for the NIF Project will be approved by the Secretary of Energy unless specifically delegated. Approval authority and/or responsibility for NIF Project documentation and reviews are presented in Tables 4-1, E-1, and E-2. The Assistant Secretary for DOE-DP has full responsibility for all NIF Project decisions not specifically retained by the Acquisition Executive. The Assistant Secretary will oversee the strategy and role of the NIF in the Stockpile Stewardship Program. 
Management responsibility for the NIF Project has been delegated to the Director of the Office of Inertial Fusion and the National Ignition Facility (DP-18), who has the authority and responsibility for the overall National Inertial Confinement Fusion Program, including overall management responsibility for the NIF. The Director has the lead for Core Science and Technology Development, long-range planning, international agreements, user group interfaces, program reviews, and budget submission as it relates to program activities.

\subsubsection{Director, Office of Inertial Fusion and the National Ignition Facility}

The NIF-related goals of the Office of Inertial Fusion and the National Ignition Facility include the following:

- To have the role of the NIF well understood by all participants and observers associated with the project.

- To maintain an environment that allows success of the project by bringing it into existence in a timely manner with capacity that fulfills the needs of the DOE and the nation.

- To ensure that the ICF Program is planned and executed consistent with the scientific basis for stockpile stewardship and activities required to meet NIF Project requirements and goals.

The Director, Office of Inertial Fusion and the National Ignition Facility, with a small project staff and matrix support from within Defense Program, is responsible for issuing DOE Project Work Authorizations, authorizing project funds, programmatically formulating and monitoring the overall project progress, and ensuring that all required DOE-HQ activities that support the project are accomplished effectively. Functions for which other DOE-HQ organizations are responsible will be conducted as part of the routine DOE management process. For example, the Office of Program Analysis and Financial Management, DP-41, is responsible for DOE-HQ program analysis functions relative to Defense Programs' mission, policy, goals and objectives, as well as budget formulation, justification, and analysis for the NIF and the ICF Program. DP-41 will advise DP-18 of the appropriateness of planned project activities in terms of resources availability and will assist in developing alternative strategies based on defined resource level.

The Director's NIF-related responsibilities also include the following:

- Establishing project policy through the Justification of Mission Need, the Project Execution Plan, and formal project direction.

- Securing resources, issuing DOE Project Work Authorizations, and overall formal project and technical guidance and direction to the NIF DOE Field Office. 
- Maintaining overview of project cost, schedule, and technical performance via the reporting system, project status review meetings, and regular communication with the NIF DOE Field and Laboratory Project Management.

- Reviewing and coordinating the approval of DOE-HQ controlled baselines and initiating critical decision and other required reviews.

- Establishing and chairing the NIF Level 1 Baseline Change Control Board to coordinate the DOE-HQ review, assessment, and action on all proposed baseline changes that are within the Level 1 approval thresholds or decision points (as identified in Tables 4-1 and E-1).

- Assisting in major project actions that may exceed the purview and authority of the DOE Field and functioning as the formal and primary point of contact for NIF Project activities within DOE-HQ.

- Providing direct involvement with the community and stakeholders concerning the overall Program mission and issues of programmatic performance.

- Maintaining a close interface with User Group and review group input, and provide technical advice when requested.

- Coordinating ICF budgets to ensure the timely completion of agreed-upon core technology development.

\subsection{DOE Field Office}

The DOE Oakland Operations Office (DOE-OAK) has been assigned the DOE Field Office responsibility for management of the NIF Project. To accomplish this as well as assure field level coordination between the NIF Project and the ICF Program, DOEOAK has created the Inertial Confinement Fusion Division (within the Associate Manager for National Security Office) whose Director serves as the NIF DOE Field Manager. DOE-OAK will provide additional matrix support to the ICF Division as required.

\subsubsection{NIF DOE Field Manager}

The NIF DOE Field Manager is responsible for the DOE project-related onsite management and field actions. Consistent with the formal project direction and funding authorization provided by DOE-HQ, the NIF DOE Field Manager's responsibilities will include the following:

- Providing DOE onsite project management, including monitoring all aspects of the project phases relative to the technical, cost, and schedule baselines, and ensuring the adequacy of the project management system.

- Directing the NIF NEPA process and environmental applications; and providing environment, safety, and health oversight for all NIF activities. 
- Issuing DOE project guidance and authorization to project participants and assuring that appropriate contract funding modifications are completed.

- Establishing and chairing the NIF Level 2 Baseline Change Control Board to coordinate the DOE Field review, assessment, and action on all proposed baseline changes that are within the Level 2 approval thresholds (see Tables 4-1 and E-1). Transmitting all proposed baseline changes that exceed the Level 2 approval thresholds with recommendations to the Level 1 Board.

- Coordinating with DOE Field matrix organizations as required to obtain support of project management activities, including the review and concurrence of DOErequired safety and environmental documents.

- Functioning as the formal communications channel within DOE Field, the NIF Laboratory Project Office, and DOE-HQ; apprising the Director, Office of Inertial Fusion and the NIF Project of any project-related field management issues.

- Participating on the project management team and encouraging full and complete informal communications among offices.

- Providing direct involvement with the community and stakeholders concerning the Project mission and issues of operational performance.

\subsection{Laboratory Lasers Directorate of the Lawrence Livermore National Laboratory}

The Laboratory Lasers Directorate supports the DOE by providing executive-level policy and planning input and by representing the NIF Project and the National ICF Program to a wide audience. The Director's responsibilities will include the following:

- Exploring and recommending to DOE, along with ICF Program management, strategic relationships among project stakeholders, laboratories, and national and international constituents.

- Obtaining community input for the purpose of consulting with and making recommendations to DOE on the overall project mission.

- Providing executive-level representation of the NIF Project/ICF Program to DOE offices, other agency and government leaders, and the private sector.

- Establishing the NIF Council, composed of individuals selected for their expertise and experience relevant to each of the project phases, to obtain independent and critical review of and advice on all project aspects.

- Selecting the Laboratory NIF Project Manager with concurrence from the Director of the Laboratory and the Director, Office of Inertial Fusion and the NIF Project. 


\subsection{NIF Laboratory Project Office}

The NIF Laboratory Project Office consists of the NIF Laboratory Project Manager and four Deputy Project Managers representing Lawrence Livermore, Los Alamos, and Sandia National Laboratories, and University of Rochester Laboratory for Laser Energetics. The Deputy Project Managers will be nominated by their respective directors and concurred by the Director, Office of Inertial Fusion and the NIF Project and the NIF Laboratory Project Manager. The NIF Laboratory Project Office, serving as the prime contractor, will be supported by key subcontractors: an Architect/Engineer, Engineering Support Contractors, and the Construction Manager.

The Lawrence Livermore National Laboratory is the lead laboratory for all WBS Level 2 elements, with support provided by the other laboratories. Lead responsibility for WBS 1.3.4, Amplifier Power Conditioning System, has been assigned to Sandia National Laboratories, and lead responsibility for WBS 1.11.3, Environment/NEPA, has been assigned to DOE-OAK, with support provided by the Argonne National Laboratory.

\subsubsection{NIF Laboratory Project Manager}

The NIF Laboratory Project Manager has the overall contractor authority and responsibility for the project's execution, overall technical direction, and allocation of funds. The NIF Laboratory Project Manager fills the key role for the physical realization of the facility, and has responsibility for implementing all plans for achieving the project activities. Responsibilities also include integrated planning, performance tracking, and reporting to ensure adequate control of all participants' activity.

The NIF Laboratory Project Manager and the Deputy Project Managers will resolve issues within Level 3 authority using the Baseline Change Control Board: Consensus resolution by the NIF management team will prevail for issues that cannot be resolved through routine negotiations between the NIF Laboratory Project Manager and the Deputy Project Managers.

The NIF Laboratory Project Manager's responsibilities include the following:

- Executing the project and ensuring that activities are properly defined and controlled.

- Monitoring progress and effecting necessary corrective actions, where required, to resolve problems and conflicts that affect project implementation.

- Interfacing as needed with the NIF DOE Field Manager and freely communicating with the Director, Office of Inertial Fusion and the NIF Project.

- Establishing and maintaining baselines (technical, cost, and schedule) in accordance with the Project Execution Plan and routinely reporting their status to the DOE.

- Controlling the NIF project configuration. 
- Establishing and chairing the NIF Level 3 Baseline Change Control Board to coordinate the Laboratory review, assessment, and action on all proposed changes. Transmitting all proposed baseline changes that exceed the Level 3 approval thresholds with recommendations to the Level 2 Baseline Change Control Board.

- Providing for the contracting, management, and technical direction of the Architect/Engineers, Engineering Support Contractors, the Construction Manager, and other contractors/vendors.

- Conducting project work in accordance with the applicable DOE Orders, institutional standards, requirements, and procedures.

- Determining that core science and technology objectives are compatible with the project needs.

- Implementing DOE assurance requirements for environment, safety, and health; quality assurance; and security.

- Appointing (with the concurrence of the Deputy Project Managers) all Laboratory NIF key personnel (those with leadership or reporting responsibilities at WBS Level 2 or higher).

\subsubsection{NIF Deputy Project Managers}

The roles and responsibilities documented in this section of the Project Execution Plan constitute the follow-on needed for the memorandum of agreement (NIF-LLNL93-018) that defined the four laboratories' project participation during the conceptual design. This Project Execution Plan is intended to alleviate the need for further Memorandums of Agreement detailing NIF principal participant roles regardless of the Project phase.

The NIF Deputy Project Managers' responsibilities, for which project funding is provided, include reporting to the NIF Laboratory Project Manager, communicating project requirements to and generating consensus and commitment from their respective organizations with respect to project issues, and executing their assigned technical areas.

The NIF Deputy Project Managers represent their laboratory's ICF program position with respect to NIF project tasks. They are the interface between project execution and ICF Program activities at their respective laboratories.

Technical work scope for the primary participants will be negotiated annually and approved by the NIF Laboratory Project Manager. It is possible for a participant to have specific WBS (i.e., subsystem) responsibilities, as well as have employees placed in a WBS activity for which it has no cost account responsibilities. The NIF Deputy Project Managers delineate the available manpower, facilities, and technical capabilities of their laboratories and commit those resources as appropriate to the accomplishment of NIF Project objectives. Specific resource contributions and technical responsibilities will be documented annually in the Project Cost Account Plans (CAPS). 
In addition to overseeing their respective laboratories' technical direction and resource management activities, they are responsible for regularly providing technical and financial data on their activities to the NIF Laboratory Project Office.

The NIF Deputy Project Managers' responsibilities include the following:

- Representing their institutions on the project and at their institutions in terms of resource allocation, priorities, and conflict resolution.

- Coordinating NIF-related reviews at and obtaining concurrence or approvals from their institutions in support of NIF Project objectives.

- Interfacing and communicating routinely with the NIF Laboratory Project Manager and NIF engineering organizations.

- Serving as members of the Level 3 Baseline Change Control Board, as required, to review proposed changes to the approved NIF baselines.

- Planning, directing, and controlling assigned project responsibilities. Providing input to internal and external project reviews.

- Providing input to cost, schedule, and technical reporting for their areas of responsibility.

- Executing their assurance responsibilities for environment, safety, and health; quality assurance; and security. 


\section{Project Execution}

This chapter describes the management processes that will be used to implement the NIF Project. The NIF Project work logic diagram, which represents the progression of project activities, is shown in Appendix B, "NIF Project Work Logic Diagram."

\subsection{Baseline Establishment}

The initial technical, cost, and schedule baselines for the NIF are formally established by approval of this Project Execution Plan and provide the basis from which all proposed future changes are measured. This is consistent with the Secretary of Energy's endorsement of Critical Decision 2, "Approval of New Start." A summary of the current baseline data is contained in the NIF Project Data Sheet (see Appendix C).

\subsubsection{Technical Baseline}

The approved NIF technical baseline is currently documented in the following publications:

- Justification of Mission Need Statement.

- Facility Functional Requirements and Primary Criteria.

- System Design Requirements.

- Subsystem Design Requirements.

- Interface Control Documents.

The complete hierarchy of criteria and their relationship is shown in Figure 4-1. As Title I and II design progresses, more System Design Requirements, Interface Control Documents, and design media in the form of top-level drawings, calculations, and specifications will be formulated. In addition, key environmental and safety documents (e.g., the Programmatic Environmental Impact Statement and Preliminary Safety Analysis Report) augment the baseline after these documents are completed and approved.

\subsubsection{Cost Baseline}

The initial NIF cost baseline, which has been validated through a DOE-FM Independent Cost Estimate, was based on the National Ignition Facility Conceptual Design Report cost estimate with associated profiles of budget authorization and outlay. This baseline was updated, revalidated with an ICE Review at the completion of Title I design, and approved by the DOE Acquisition Executive (Level 0 Baseline Change Control Board) in March 1997. The Project Data Sheet contains the funding profile and is the basis for the baseline cost plan, which is summarized at Work Breakdown Structure Level 2 in Appendix D. 


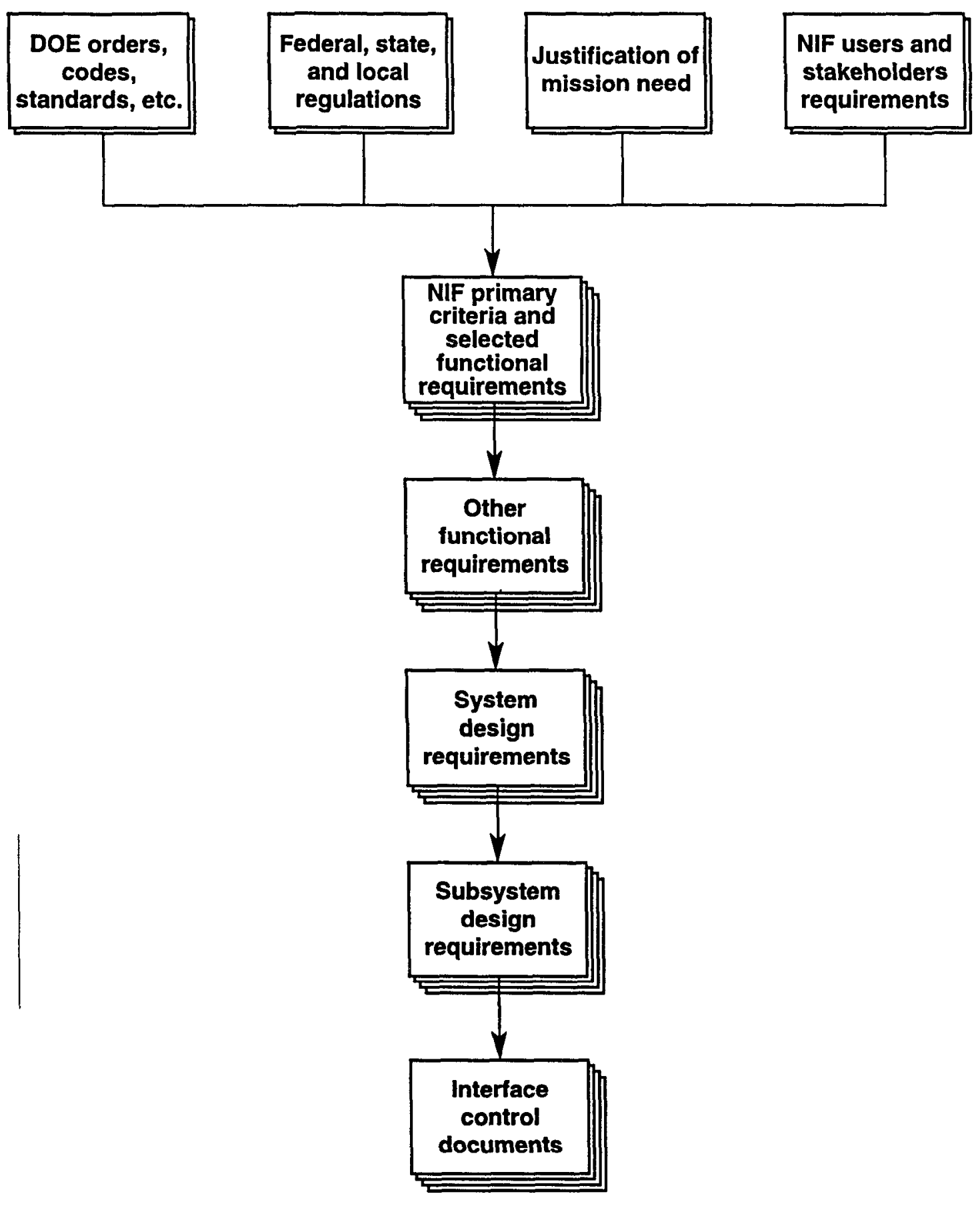

40-00-0494-1775pbo5

Figure 4-1. Relational Hierarchy of Criteria. 


\subsubsection{Schedule Baseline}

The National Ignition Facility Conceptual Design Report contained the initial project schedule baseline in the form of a time-phased logic diagram and the key milestone listings. The critical-path activities are identified on the schedule. The schedule baseline was updated at the completion of the Title I design. Appendix E contains the NIF Summary Integrated Project Schedule, Major Milestones, and Critical Decisions (see Figure E-1).

\subsection{Baseline Change and Contingency Control}

Establishment and maintenance of baselines are the most important aspects of project control. Changes to baselines will be carefully controlled to avoid loss of control and distortion in performance reporting. The purposes of the project change control system are to assure that:

- The cost, schedule, and technical impacts of proposed changes are developed and considered by all appropriate parties.

- The collected evaluations are considered in the approval or rejection of the proposed changes.

- All appropriate parties are informed of proposed changes and their disposition.

- Baseline documentation is controlled and updated as appropriate to reflect approved changes.

- Action on all change requests is deliberate and without undue delay, but carried out without interfering disproportionately with project progress.

\subsubsection{Baseline Change Control and Configuration Control}

Technical, cost, and schedule baselines established upon approval of this Project Execution Plan will be subject to Baseline Change Control Board review process. Baseline Change Control Boards will be established at three levels to approve, disapprove, or endorse (i.e., recommend approval to a higher-level Baseline Change Control Board) all proposed baseline changes. The Energy System Acquisition Advisory Board (ESAAB), a forum that provides advice, assistance, and recommendations on critical decision points to the DOE Secretary, will be the Board to consider and dispose of baseline change proposals within the Acquisition Executive Level 0 Authority. Although established outside the NIF Baseline Change Control Board process, the ESAAB is integral to project control at the Acquisition Executive level.

The change board hierarchy is shown in Figure 4-2 and change thresholds are listed in Table 4-1. Each lower-level board that approves a baseline change will provide the next higher-level board with a copy of the approved baseline change package and will endorse all proposed changes to be considered by the next higher-level board. This process ensures proper oversight of all proposed changes, which can originate at any 
level in the project, but must be fully evaluated at Level 3 . The thresholds determine the appropriate management approval level.

Membership of Levels 1,2, and 3 Boards will be at the discretion of the respective board chairperson. Authority and responsibilities of each board are to be defined in its decision-making charter. The Levels 1 and 2 Change Board Chairpersons shall have full decision-making authority; the board is an advisory rather than a voting board and the Chairperson, at his or her discretion, may provide disposition of a requested change without conducting a board meeting. The Level 3 Board is composed of voting members, however, who will collectively decide on change disposition at formal meetings.

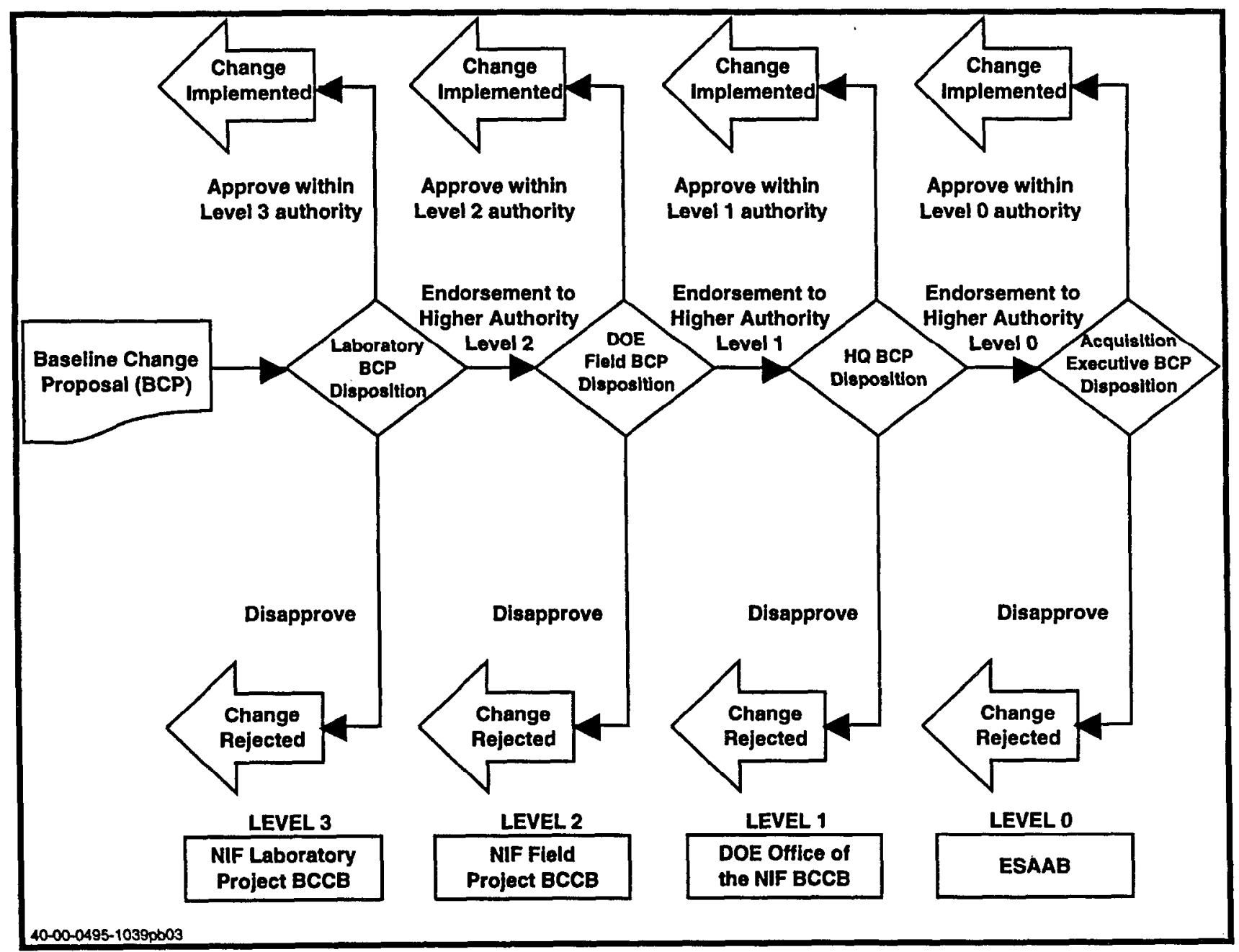

Figure 4-2. Baseline Change Control Board (BCCB) Hierarchy. 
Table 4-1. Baseline Change Control Levels.

\begin{tabular}{|c|c|c|c|c|}
\hline \multicolumn{5}{|c|}{$\begin{array}{l}\text { National Ignition Facility (NIF) } \\
\text { Summary of Baseline Change Control Thresholds }\end{array}$} \\
\hline & $\begin{array}{c}\text { DOE } \\
\text { Acquisition Executive } \\
\text { (Level 0) } \\
\end{array}$ & $\begin{array}{c}\text { DOE Office of } \\
\text { the NIF } \\
\text { (Level 1) } \\
\end{array}$ & $\begin{array}{l}\text { DOE NIF } \\
\text { Field Office } \\
\text { (Level 2) }\end{array}$ & $\begin{array}{c}\text { NIF Laboratory Project } \\
\text { Office } \\
\text { (Level 3) }\end{array}$ \\
\hline $\begin{array}{l}\text { Technical } \\
\text { (Scope) } \\
\text { Baseline } \\
\text { Thresholds }\end{array}$ & $\begin{array}{l}\text { Any deviation from } \\
\text { the NIF Justification } \\
\text { of Mission Need }{ }^{1}\end{array}$ & $\begin{array}{l}\text { Any deviation } \\
\text { from primary } \\
\text { criteria and } \\
\text { selected } \\
\text { functional } \\
\text { requirements } \\
\text { (as identified in } \\
\text { reference 3) }\end{array}$ & $\begin{array}{l}\text { Any deviation } \\
\text { from functional } \\
\text { requirements, } \\
\text { other than } \\
\text { selected } \\
\text { functional } \\
\text { requirements } \\
\text { (as identified in } \\
\text { reference 3) } \\
\end{array}$ & $\begin{array}{l}\text { - Any deviation } \\
\text { from system } \\
\text { design } \\
\text { requirements } \\
\text { that affect } \\
\text { system } \\
\text { performance }\end{array}$ \\
\hline $\begin{array}{l}\text { Schedule * } \\
\text { (Milestone) } \\
\text { Baseline } \\
\text { Thresholds }\end{array}$ & $\begin{array}{l}\text { Changes to Level } 0 \\
\text { milestones in excess } \\
\text { of six months }\end{array}$ & $\begin{array}{l}\text { Changes to } \\
\text { Level } 1 \\
\text { milestones in } \\
\text { excess of six } \\
\text { months }\end{array}$ & $\begin{array}{l}\text { Changes to } \\
\text { Level } 2 \\
\text { milestones in } \\
\text { excess of six } \\
\text { months }\end{array}$ & $\begin{array}{l}\text { - Changes to } \\
\text { Level } 3 \\
\text { milestones in } \\
\text { excess of six } \\
\text { months }\end{array}$ \\
\hline $\begin{array}{l}\text { Cost (Dollar) } \\
\text { Baseline } \\
\text { Thresholds }\end{array}$ & $\begin{array}{l}\text { - Changes to } \\
\text { TEC/TPC in excess } \\
\text { of } \pm 50 \mathrm{M}\end{array}$ & $\begin{array}{l}\text { - Changes } \\
\text { between } \pm \$ 25 \mathrm{M} \\
\text { and } \pm \$ 50 \mathrm{M} \text { that } \\
\text { do not affect } \\
\text { the TEC/TPC } \\
\text { Changes to } \\
\text { TEC/TPC less } \\
\text { than } \pm \$ 50 \mathrm{M} \\
\text { - Changes to } \\
\text { Project Data } \\
\text { Sheet funding } \\
\text { profile }\end{array}$ & $\begin{array}{l}\text { - Changes } \\
\text { between } \pm \$ 5 \mathrm{M} \\
\text { and } \pm \$ 25 \mathrm{M} \text { that } \\
\text { do not affect the } \\
\text { TEC/TPC } \\
\text { - Changes } \\
\text { requiring } \\
\text { contingency } \\
\text { allocations of } \\
\text { greater than } \\
\$ 5 \mathrm{M} \\
\text { - Changes to } \\
\text { distribution of } \\
\text { funds between } \\
\text { participants }\end{array}$ & $\begin{array}{l}\text { - Changes less } \\
\text { than } \pm \$ 5 \mathrm{M} \text { that } \\
\text { do not affect the } \\
\text { TEC/TPC } \\
\text { - Changes } \\
\text { requiring } \\
\text { contingency } \\
\text { allocations of } \\
\text { less than } \$ 5 \mathrm{M} \\
\text { - Changes that } \\
\text { are greater than } \\
5 \% \text { of remaining } \\
\text { total Project } \\
\text { contingency } \\
\text { will have NIF } \\
\text { DOE Field } \\
\text { Manager } \\
\text { participation }\end{array}$ \\
\hline
\end{tabular}

* Refer to Table E-1 for identification of milestones by level.

The Level 1 Board for DOE's Office of Inertial Fusion and the NIF Project will be staffed appropriately to maintain the required departmental expertise to make sound judgments. For example, DP-41 must be able to review any changes to the baseline scope, schedule, and/or cost that could affect Departmental, Office of Management and Budget, and congressional policies and controls that might change the current construction project data sheet. 
For directed changes, the DOE-HQ directive will be the authorization for implementing the change (directed changes do not require change board approval). The NIF Laboratory Project Office will determine and document resulting impacts to other baselines, when appropriate, and will provide information copies of the change impacts to appropriate management levels.

If changes (either approved or directed) exceed congressionally mandated thresholds, congressional notification is required prior to approval and authorization to proceed. All congressional notifications must be coordinated through the Chief Financial Officer prior to submission in accordance with DOE Order 135.1, Budget Execution-Funds Distribution and Control (September 1995).

The NIF Project will control the project documents listed in Table E-2 through the process of issuing, reviewing, and approving changes. These are the chief change processes for project documents and are central to the NIF configuration control system, which will ensure that the project documents are current with the actual as-installed NIF systems. The configuration control system will be described in the NIF Configuration Management Plan and the implementing project procedures.

\subsubsection{Contingency Control}

Project contingency is the planned funds identified in the Plant-and-CapitalEquipment-funded NIF Total Estimated Cost activity to cover unforseeable but "inscope" situations. Contingency was first established in the conceptual design process and documented in the National Ignition Facility Conceptual Design Report. It will be updated as a consequence of Title I and Title II design. A DOE Order allows contingency on Operating-Expense-funded NIF Other Project Costs, but no contingency allowance has been made.

For the NIF Project, allocations of contingency greater than $\$ 500,000$ will be controlled through Change Control Board actions. For these changes, a master contingency $\log$ will be kept by the Level 3 Board to record each allocation. Contingency will be monitored and controlled on a total Project basis.

Each year's Plant and Capital Equipment appropriation will include a portion of the total Project contingency. The Level 2 Change Control Board will approve all allocations of contingency greater than $\$ 5$ million. The Level 3 NIF Laboratory Project Office change board will approve contingency allocations of less than $\$ 5$ million. Changes that are greater than $5 \%$ of the remaining total Project contingency will have NIF DOE Field Manager participation.

The NIF Laboratory Project Manager is authorized to allocate up to $\$ 500,000$ of contingency without convening the Level 3 Change Control Board, subject to the allocation being within $5 \%$ of the remaining total Project contingency. Notification of these allocations less than or equal to $\$ 500,000$ will go to all Change Control Boards, as well as be recorded in the master contingency log. 


\subsection{DOE Budget Authorization Process}

NIF funding requests are made as part of the DOE annual budget request process, for inclusion in the Defense Programs' Corporate Review Budget, the Office of Management and Budget, and the Congressional budget submissions. A DOE independent validation of the NIF annual budget request may be performed by DOE for each fiscal year for which funds are requested.

The NIF Laboratory Project Manager must establish annual budget guidance for the project participants based on the negotiated scope of work to be accomplished by each. This will yield the distributions recommended to the NIF DOE Field Office and the Office of Inertial Fusion and the NIF Project for their request to DP-41. Funding distribution will be coordinated by the Office of Inertial Fusion and the NIF Project, the DOE Field Manager, and the NIF Laboratory Project Office with review by DP-41 for conformity with congressional structures and Defense Programs' policies, procedures, and priorities.

After Congressional authorization/appropriation of NIF funds, DOE-HQ will distribute the NIF funds to the appropriate DOE Field Operations Offices via the approved financial plan process. The DOE Work Authorization System/Prime Contract Modification Process will be used by DOE for the general authorization of funds for work at the participating laboratories.

The NIF DOE Field Office will use the DOE Project Authorization System to provide more detailed direction to LLNL and UR-LLE for use of the appropriated funds and/or the start of major project activities. It will forward the same type of information to the Albuquerque Operations Office for its issuance of Project Authorization Directives to LANL and SNL.

\subsection{Procurement and Contracting}

The NIF Project Acquisition Plan was completed in April 1996 and addresses the strategy for vendor facilitization, design, equipment procurement, construction, and other services. The NIF Procurement Plan, complete at the conclusion of Title I design, identifies all individual NIF procurements and contracts over $\$ 250,000$, and describes the estimated cost and schedule. In addition, a detailed annual commitment plan is developed by the NIF Laboratory Project Office prior to the start of each fiscal year.

Procurement solicitation and award actions for the project will be accomplished by a dedicated procurement team at LLNL that will be responsible for as many of the NIF acquisitions as practicable. However, all the participating laboratories will be able to make procurements as needed in accordance with their prime contracts or cooperative agreement in effect between them and the DOE. 


\subsection{Reviews}

\subsubsection{DOE Status Reviews}

Table 4-2 lists the DOE NIF Project Status reviews. These reviews are integral to the project technical, schedule, and cost tracking and reporting processes.

Table 4-2. NIF Project Status Reviews.

\begin{tabular}{|l|c|c|}
\hline \multicolumn{1}{|c|}{ Project Status Reviews } & Reviewers & Presenters \\
\hline \hline Monthly Status* & DOE Field NIF Project Office & NIF Laboratory Project Office \\
\hline Quarterly Progress & $\begin{array}{c}\text { DOE Field NIF Project Office, } \\
\text { DP-18, DP-41 }\end{array}$ & NIF Laboratory Project Office \\
\hline Annual Budget Validation & DOE FM-50 & $\begin{array}{c}\text { DOE Office of Inertial Fusion } \\
\text { and the NIF Project, NIF } \\
\text { Laboratory Project Office }\end{array}$ \\
\hline
\end{tabular}

* There will not be a Monthly Review when there is a Quarterly Review.

\subsubsection{Independent Reviews}

There are several user and independent review groups associated with the NIF project, all of whom report to the DOE. The NIF user groups interact with the DOE and the NIF Laboratory Project Office through workshops and collaborative position papers. Other special reviews, such as the one in support of KD1' that satisfied the Dellums' Process (public review of the impact of NIF on nonproliferation), will be defined by Congress or the DOE as required.

\subsection{Performance Control and Reporting Systems}

Project control and reporting requirements are outlined in the Life-Cycle Asset Management Order 6 and the Joint Program Office Direction on Project Management ${ }^{7}$. These documents provide guidance for a graded approach to project management to minimize overall project cost and schedule risk. The project control system is closely integrated with the baseline change control and work authorization processes, and will provide the required status and variance analysis for the specified reporting period. The NIF Project will require an integrated project-control system to provide effective planning and reporting, as well as day-to-day management capabilities. This system will:

- Identify and organize all of the work scope required to complete the project.

- Provide the means to break the work scope into tasks, with a time-phased budget and resource plan.

- Measure and report actual costs and commitments against the approved task plans and established baselines. 
- Generate and maintain the cost and schedule baseline estimates for the project.

- Forecast future funding requirements.

- Provide the basis for project budget submissions and validations.

- Monitor and control procurement and contracting activities and commitments.

\subsubsection{Control Systems}

Each month, based on the current month and cumulative data, the responsible Cost Account Manager must prepare a status report for approval by the cognizant Associate Project Engineer. If variance thresholds are exceeded, the status report will include a variance analysis. The variance analysis report will identify the nature of the variance, the cause of the variance, the expected impact on the project, a recovery plan, and a current estimate-to-complete the work. The NIF Laboratory Project Office summarizes the variance reports and maintains an estimate-at-completion for each work breakdown structure element.

The schedule, which also contains a critical path network, is maintained as a project planning and measurement tool. The individual tasks in the network support the effort and budgets on the Cost Account Plans. At the end of every month, each Associate Project Engineer will provide a schedule update, including changes to planned activity durations, changes to planned start and completion dates, actual start and completion dates, additions and deletions of activities, logic changes, and budget changes.

In the event of major changes in the project scope, schedule, and/or funding profile, the project will be rebaselined. Rebaselining consists of modifying plans for all or part of the work breakdown structure to eliminate current variances. All changes to the baseline are subject to Baseline Change Control Board review and are documented.

\subsubsection{Reporting}

The NIF Laboratory Project Office will be responsible for collecting, maintaining, and integrating sufficient information to satisfy all of the project management reporting requirements.

Each project participant shall maintain complete financial data at all work breakdown structure levels for assigned work. At work breakdown structure Level 3, monthly and cumulative planned versus actual costs and commitments, with annual estimates to complete, will be reported to the NIF Laboratory Project Office by the 6 th work day after the end of the reporting period. At the same time, each participant shall also report monthly technical and schedule progress toward work completion as of the end of each calendar month. The NIF Laboratory Project Office will prepare and distribute monthly and quarterly reports to the DOE based on the integration of monthly information obtained from all project participants. Standard variance reports will be provided on work breakdown structure Level 2 elements and selected Level 3 elements for cumulative cost and/or commitment variances that exceed $\$ 100,000$ or $10 \%$ of the annual established baseline, whichever is greater. 
Monthly reports (prepared for October, November, January, February, April, May, July, and August) shall be transmitted from the NIF Laboratory Manager to the NIF DOE Field Manager by the 20th work day after the end of the month, with copies to the Director of the Office of Inertial Fusion and the NIF Project (DP-18).

Quarterly reports (prepared for October-December, January-March, April-June, and July-September) shall be transmitted by the 20th work day after the end of the quarter from the NIF Laboratory Project Manager to the NIF DOE Field Manager. After addition of a NIF DOE Field Manager's assessment, quarterly reports shall be transmitted by the 25th work day after the end of the quarter from the NIF DOE Field Manager to the Director of the Office of Inertial Fusion and the NIF Project (DP-18), whose office will distribute to other DOE-HQ organizations as needed.

Table F-1 is an overview of reporting requirements that will be satisfied by the NIF Project Reporting System.

\subsection{Assurances}

The predominant assurance objective is that the NIF will operate in a safe, secure, and environmentally sound manner, and will ensure the reliable performance of the test program specified in the NIF Experimental Plan. To achieve these top-level objectives, the project will establish formal programs for quality assurance; security; and safety; environmental, and health protection. Several master plans will be prepared: a Quality Assurance Program Plan; a Security Plan; and an Environmental, Safety, and Health Management Plan. Key outputs of the assurance program include the Quality Assurance and Security Procedures; Quality Assurance files; Acceptance Test Procedures; Operational Test Procedures; Preliminary Hazards Analysis; Preliminary Safety Analysis Report; Final Safety Analysis Report; and environmental permits.

\subsubsection{Quality Assurance}

Project quality assurance will be planned and managed consistent with the NIF Quality Assurance Program Plan, prepared in accordance with DOE Order 5700.6C, "Quality Assurance." Each phase of the project may require significantly different quality assurance requirements; therefore, the Quality Assurance Program Plan and implementation procedures will be revised as appropriate. Revisions are included as key management activities in the integrated Project schedule prior to the start of each new phase.

The Quality Assurance Program Plan identifies the quality assurance requirements and measures for controlling work on the project. The Plan:

- Provides the base requirements (e.g., preparation and control of criteria, control of procured items, nonconforming item disposition) in a phased manner to meet the project's technical requirements. 
- Initiates core quality assurance elements in a graded approach to mitigate or eliminate the risk of component or system failure.

- Provides the quality assurance basis to integrate individual activities or interface with related activities (e.g., target fabrication).

- Provides a single project document showing how all applicable DOE quality assurance requirements will be met.

\subsubsection{Risk and Graded Approach}

Risk management is based on a graded approach in which levels of risk are assessed for project activities or elements. This assessment is based upon the potential consequences of activity or element failure, as well as the probability of occurrence. The level and formality of the quality assurance requirements are tied to the potential failure consequences. Risk minimization is promoted by planning fallback positions, particularly in manufacturing readiness (e.g., using existing methods for crystal growth instead of rapid-growth KDP methods or using batch pouring of laser glass if the continuous pouring method is unsuccessful).

Three quality levels will be utilized associated with activity having high, medium and low impacts to the project. The quality level is defined in terms of potential impact, in the event of failure, on:

- Environment, public safety, and health-These threats are assessed in the context of Federal, State, and Local laws and DOE Orders.

- Worker safety.

- Technical performance and/or maturity-Technical performance is measured by considering the loss of facility, activity, or element performance in the context of design criteria, such as System Design Requirements. Technical maturity can be described as how well developed an item or system is and whether or not it is reasonably stable in terms of design, procurement, or use (i.e., an item that is in the early stages of development would be considered immature).

- Project cost-The impact on project cost is measured by the replacement or repair cost. Thresholds are set by the ability of the project to absorb unexpected cost due to failure.

- Project schedule-The impact on project schedule is judged by determining the effect of an unexpected delay.

A primary task associated with writing and implementing the subtier quality assurance plans for lower-level work breakdown structure elements (i.e., Level 2 and below, major systems and subsystems) will be to assign the proper quality level to project activities or elements. Each Systems Engineer will identify the appropriate quality level for the project activities or elements for which he has responsibility. 


\section{Method of Accomplishment}

\subsection{Environment, Safety, and Health Planning}

The Environment, Safety, and Health Management Plan will describe how the NIF Project will ensure the health and safety of workers and will protect the public and the environment. It will describe the policy, responsibilities, and documented evaluations and regulatory approvals that will be obtained prior to the beginning of construction (e.g., Preliminary Safety Analysis Report, NEPA determination, and environmental permits) and then prior to operation (e.g., Final Safety Analysis Report, Operational Readiness Reviews, environmental permits). The plan will describe each area (radiation protection, safety, environmental impact; e.g., waste generation, effluents, etc.) in a specific section.

The NIF Environment, Safety, and Health Implementation Plan will be approved by the NIF Laboratory Project Manager, who will provide copies of the plan to the NIF DOE Field Manager and the Office of Inertial Fusion and the NIF Project.

\subsubsection{NEPA Determination and Site Selection}

The NIF is included as a section of the Programmatic Environmental Impact Statement (PEIS) for Stockpile Stewardship and Management. The Notice of Intent for the PEIS states that the NEPA document is sufficiently detailed to address site selection, construction, and operation of the NIF. The Record of Decision (ROD) resulting from the PEIS was issued in December 1996.

With the PEIS completed, a Mitigation Action Plan has been prepared to mitigate the environmental impacts presented in the PEIS and the ROD. Also, the environmental monitoring program has prepared a baseline for the selected site, and the environmental permits for construction and operation are being obtained from the appropriate federal, state, and local agencies.

The following sequence outlines the activities required to allow Title II Design and site construction to proceed on schedule:

- The Notice of Intent of the Stockpile Stewardship and Management Programmatic Environmental Impact Statement was published in the Federal Register in June 1995 (FR 31291).

- Input and feedback on the issues to be considered in the Programmatic Environmental Impact Statement were obtained from public meetings, and the DOE has prepared an implementation plan that forms the basis for the preparation of the Draft Programmatic Environmental Impact Statement.

- The NIF NEPA documentation was prepared as a separate volume of the Programmatic Environmental Impact Statement on Stockpile Stewardship and Management. 
- The NIF Environmental Volume describes all of the environmental impacts of constructing and operating the NIF at the preferred and alternative sites. It also discusses the consequences of the "no action" alternative.

- The Draft Programmatic Environmental Impact Statement was reviewed by the public and the comments were incorporated into a Final Programmatic Environmental Impact Statement, which was issued for public review.

- Following completion of the Final Programmatic Environmental Impact Statement, the DOE published a Record of Decision with Lawrence Livermore National Laboratory as the chosen site. For the NIF, this Record of Decision includes the programmatic decisions on purpose, need, and site selection. A positive decision on the project-specific analysis of the environmental impacts of NIF construction and operations allows for site preparation and building excavation to begin (after Critical Decision 3).

- Critical Decision 3 was issued on March 7, 1997, by DOE.

- With the NEPA determination complete, and the Mitigation Action Plan issued, the environmental permits required for construction are being obtained and the site characterization baseline will be frozen for the environmental monitoring program. Prior to operation, environmental permits required for operation will be obtained from the Environmental Protection Agency and state and regional authorities.

\subsubsection{Safety Documents}

The primary safety documents are the Preliminary Hazards Analysis, the Preliminary Safety Analysis Report (PSAR), and the Final Safety Analysis Report. In addition, Facility Safety Procedures and appropriate Operational Safety Procedures will be prepared prior to operation. The NIF will be added to the site Emergency Preparedness Plan.

The Preliminary Safety Analysis Report was started based on the conceptual design and confirmed the facility hazard category, which was first established by the Preliminary Hazards Analysis. The Final Safety Analysis Report will be based on Title II Design and will be one of the key documents required for the Operational Readiness Review.

The PSAR was completed in May 1996, was approved by LLNL in September 1996, and received DOE/OAK concurrence in October 1996.

\subsection{NIF Design}

The NIF design began with operating-funded conceptual and advanced conceptual designs. This is followed by Plant and Capital Equipment funded Title I, II, and III Designs. 


\subsubsection{Conceptual and Advanced Conceptual Design}

The conceptual design was completed in May 1994 by the staff of the participating laboratories. Keller and Gannon contractors provided designs of the conventional facilities and equipment. The conceptual design effort included the following:

- Criteria preparation.

- Complete design description.

- Quality Assurance Program Plan.

- Preliminary Hazards Analysis.

- Detailed cost and schedule estimates.

The Conceptual Design Report was subjected to an Independent Cost Estimate review. The advanced conceptual design phase will further develop the design, and is the phase in which all of the criteria documents that will govern Title I Design are reviewed and updated.

\subsubsection{Title I, II, and III Design}

This section describes the three phases of Plant and Capital Equipment funded design for the NIF.

5.2.2.1 Title I Design. In fiscal year 1996, Title I Design began with the contract award for the Architect/Engineers and a Construction Management firm for the design and assistance in the construction of the (1) NIF Laser and Target Area Building and (2) Optics Assembly Building. Title I Design started with the base of conceptual and advanced conceptual design, including the comments from the design reviews. Beginning with a review of the requirements documents (see Figure 4-1) and identification of revisions requiring Baseline Change Control Board action, work proceeded to include the following:

- Developing advanced design details to finalize the building and the equipment arrangements and the service and utility requirements.

- Reviewing project cost estimates and integrated schedule in relation to the baselines for potential revision through Baseline Change Control Board process.

- Preparing procurement plans for the NIF Acquisition Plan.

- Conducting design reviews at the midpoint and completion of Title I Design.

- Completing the Preliminary Safety Analysis Report and NEPA documentation started during conceptual design.

- Planning for and commencement of constructibility reviews by the Construction Manager.

Title I Design was completed in November 1996 and was followed by an ICE review. 
5.2.2.2 Title II Design. The Title II Design will provide the following:

- Construction and equipment procurement packages, including calculations, specification, and other supporting documentation. These procurement packages and other detailed design media will undergo design reviews prior to approval for construction and procurement release.

- Construction cost estimate and schedule.

- Acceptance Test Procedures and the acceptability criteria for tested components (e.g., pumps, power conditioning, special equipment).

The Title II Design overlaps procurement and construction activities. It also forms the basis for the Final Safety Analysis Report.

5.2.2.3 Title III Design. Title III engineering represents the engineering necessary to support the construction and equipment installation. The main activities are to perform the engineering necessary to resolve issues that may arise during construction (e.g., fit problems, interferences, etc.). Title III engineering results in the final as-built drawings that represent the NIF configuration.

\subsection{Construction and Equipment Procurement and Installation}

Based on the March 7, 1997, Critical Decision 3, which required the completion of the NEPA documentation and the Preliminary Safety Analysis Report, construction will begin with the site preparation and excavation forming the critical-path activities. In addition to the completion of the NEPA and safety documents, there must be sufficient Title II Design completed to support bid of the major construction and equipment procurements. The Construction Manager will describe the construction strategy in the Construction Plan. The critical-path construction activities include both the Laser and Target Area Building and the Optics Assembly Building (where special equipment assembly and staging will take place). In addition, the site support infrastructure needed to support construction and special equipment staging will be put in place. At the same time, procurements on the critical-path will begin following the plan established in the NIF Procurement Plan.

The special and engineered equipment will be delivered, staged, and installed as phased beneficial occupancy of the Laser and Target Area Building is achieved. This is a complex period in which conflicting priorities may occur because construction, equipment installation, and acceptance testing will be occurring. The Construction Manager will manage and integrate the activities to avoid potential interferences affecting the schedule. The construction, equipment installation, and acceptance testing will be supported by Title III inspection and field engineering, which will include resolving construction and installation issues and preparing the final as-built drawings. After installation, the facility and equipment will be subjected to the Acceptance Test Procedures, which mark the turnover of the construction and procurement activities to 
the operations organization for operational testing and start-up (see Section 5.4). The NIF Project will provide sufficient construction spares and operating spares for inital operation.

\subsection{Operational Testing and Start-up}

The operational planning begins early in the project to ensure readiness for start-up with the preparation of the Operational Test Procedures for integrated system testing. The integrated system activation and start-up testing will begin with the early activation of the first laser bundle. An Operational Readiness Review will be conducted by the site organization prior to the start of early operations of the first bundle, and the results will be validated by the DOE Field Office. The Operational Readiness Review requires that the Final Safety Analysis Report be completed and approved (including the documented operating/maintenance procedures, operating staff training, and asbuilt design documentation). As each of the twenty-four bundles of the NIF become operational it would then be turned over to the National Inertial Confinement Fusion Program and the NIF Operations Organization.

\subsection{Project Completion}

The complete set of NIF criteria is contained in the NIF Functional Requirements and Primary Criteria (FR/PC). ${ }^{3}$ These are the criteria which NIF is required to meet when fully operational. However, early operation of NIF by the Program will be achieved by a phased transition to Program operations before Project completion. This enables the Program to begin experimental operations in support of Stockpile Stewardship and other programmatic missions at the earliest possible date, as NIF performance capability is building up toward the eventual goals set out in the FR/PC.

The overall strategy for NIF construction and start-up significantly benefits both the Project and Program by emphasizing early start-up of a single ( 8 beam) laser bundle. For the Project, it is an early verification of the operational capability of the basic functional unit of the laser system. For the Program it provides early experimental capability. The first bundle of eight beamlines will be installed, started up, and operated well in advance of the start-up of the rest of the laser system, to allow lessonslearned to be incorporated in the remainder of the Project production hardware. Following installation and acceptance testing of the first bundle in one of the laser bays, the focus of Project activity will turn to installation of the full NIF system, starting in the other laser bay and proceeding bundle-by-bundle. Completion of the installation and start-up of Special Equipment will be conducted in parallel with operation of the first bundle. 
By the end of the Project, the status of the facility will be as follows:

- All conventional facility construction will be completed and all permanent hardware will be installed. Optical Line-Replaceable Units will be assembled and installed as required to support start-up. Acceptance tests will be performed at the subsystem level on all special equipment: laser components, structures, beam controls and diagnostics. All equipment will be integrated with the computer control system. Sufficient spares will be available for construction and initial first bundle operation.

- One bundle will have been operated sufficiently to demonstrate the basic performance capability of the system.

- The Operational Readiness Review for first bundle will be complete.

- One-half of the laser system (two clusters in Laser Bay 1) will be operational having completed a phased start-up sequence with demonstrated energy delivery of $5 \mathrm{~kJ} /$ beamline at $0.35 \mu \mathrm{m}$ to target chamber center. The remaining two clusters in Laser Bay 2 will be ready for start-up.

By the completion of the Project, all requirements in the FR/PC will be met, except for specific performance-related requirements as discussed in the NIF Project Completion Criteria.

\subsection{Security}

The NIF Project involves classified data requiring safeguarding; the project itself represents a large investment of government funds in assets that must be protected. The Functional Requirements and the System Design Requirements contain guidance on security-system design requirements. A security plan will be prepared and submitted for DOE approval prior to experimental operations. The plan will describe the DOE requirements and compliance of the NIF design (e.g., access control, vaults, secure transfer lines, etc.) and administrative procedures that implement them. It will also describe the site security organization and interface to the NIF Project security team. Issues related to transparency of experimentation by the user community and international collaboration will be addressed in the NIF Security Plan. 


\section{Effective Date and Amendments}

This National Ignition Facility Project Execution Plan will be implemented immediately upon approval. This approved plan is a controlled document and provides the initial Project baseline. All project baseline revisions are subject to the Baseline Change Control Board system requirements as discussed in Chapter 4. Updated technical, schedule, and cost plans resulting from Baseline Change Control Board decisions, as well as appendix changes of this document, will be appended to this plan without concurrence of the original approvers.

The initial Project Execution Plan required approval by the Assistant Secretary for Defense Programs. Subsequent revisions to the body of the document (excluding Table 4-1) will require approval of the Director of the Office of Inertial Fusion and the NIF Project, the NIF DOE Field Office Manager, and the NIF Laboratory Project Office Manager. 


\section{References and Notes}

1. U.S. Department of Energy, National Ignition Facility Justification of Mission Need, 1993.

2. U.S. Department of Energy, Key Decision 1 Approval Letter for the National Ignition Facility, October (1994).

3. National Ignition Facility Functional Requirements and Primary Criteria, Rev. 1.6, NIF-0001006, Lawrence Livermore National Laboratory, March (1996).

4. Project Charter for the National Ignition Facility Conceptual Design, March (1993).

5. Memorandum of Understanding Regarding the Relationship between the Office of the National Ignition Facility and the Office of Research and Inertial Fusion, March 27, 1995.

6. U.S. Department of Energy, Life-Cycle Asset Management Order, DOE Order 430.1, August (1995).

7. United States Department of Energy Joint Program Office Direction on Project Management, January (1996).

8. NIF Project Completion Criteria (NIF-0001587). 


\section{Appendix A}

\section{NIF Project Summary Work Breakdown Structure}

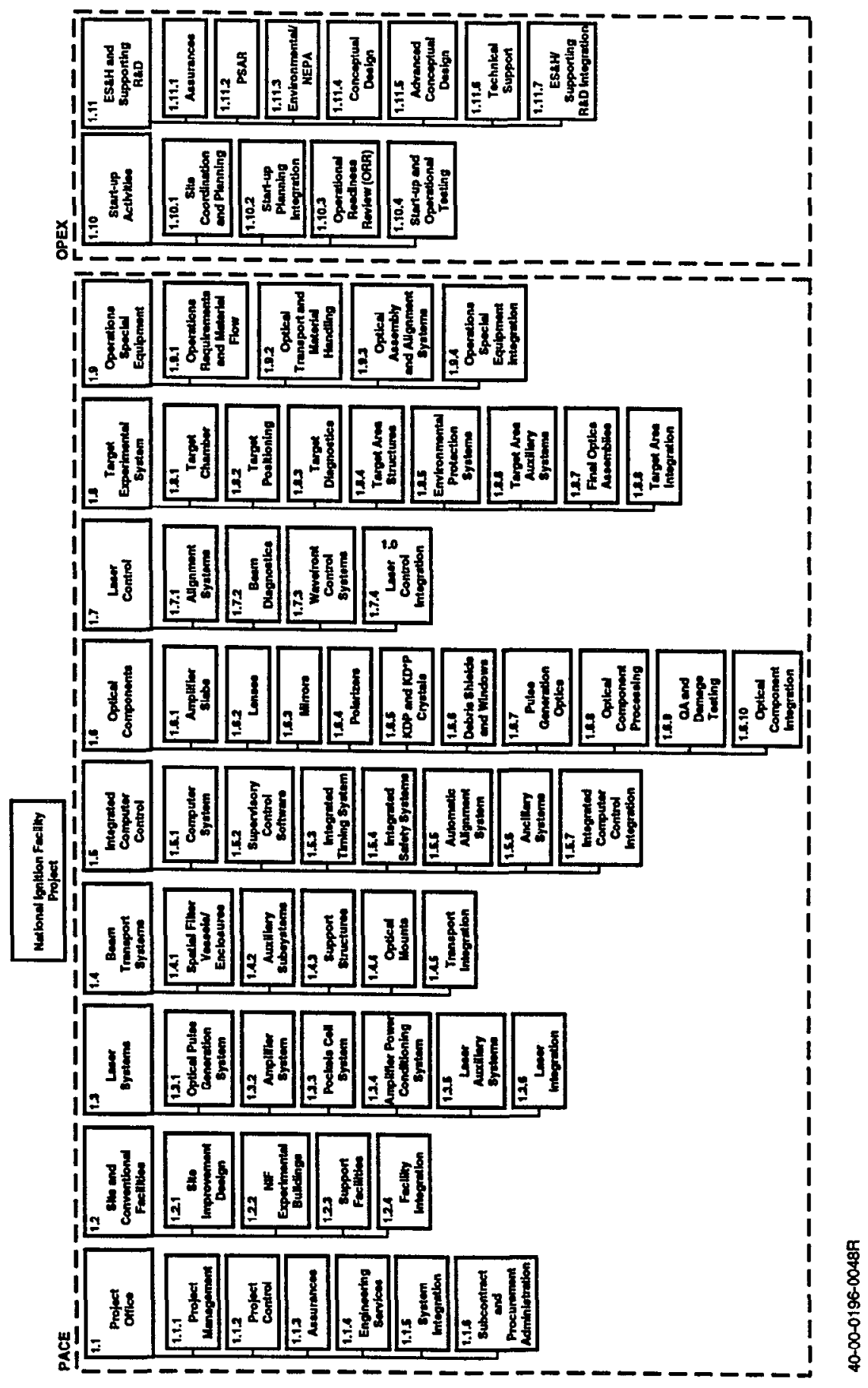

Figure A-1. NIF Project Summary Work Breakdown Structure. 


\section{Appendix B}

NIF Project Work Logic Diagram 


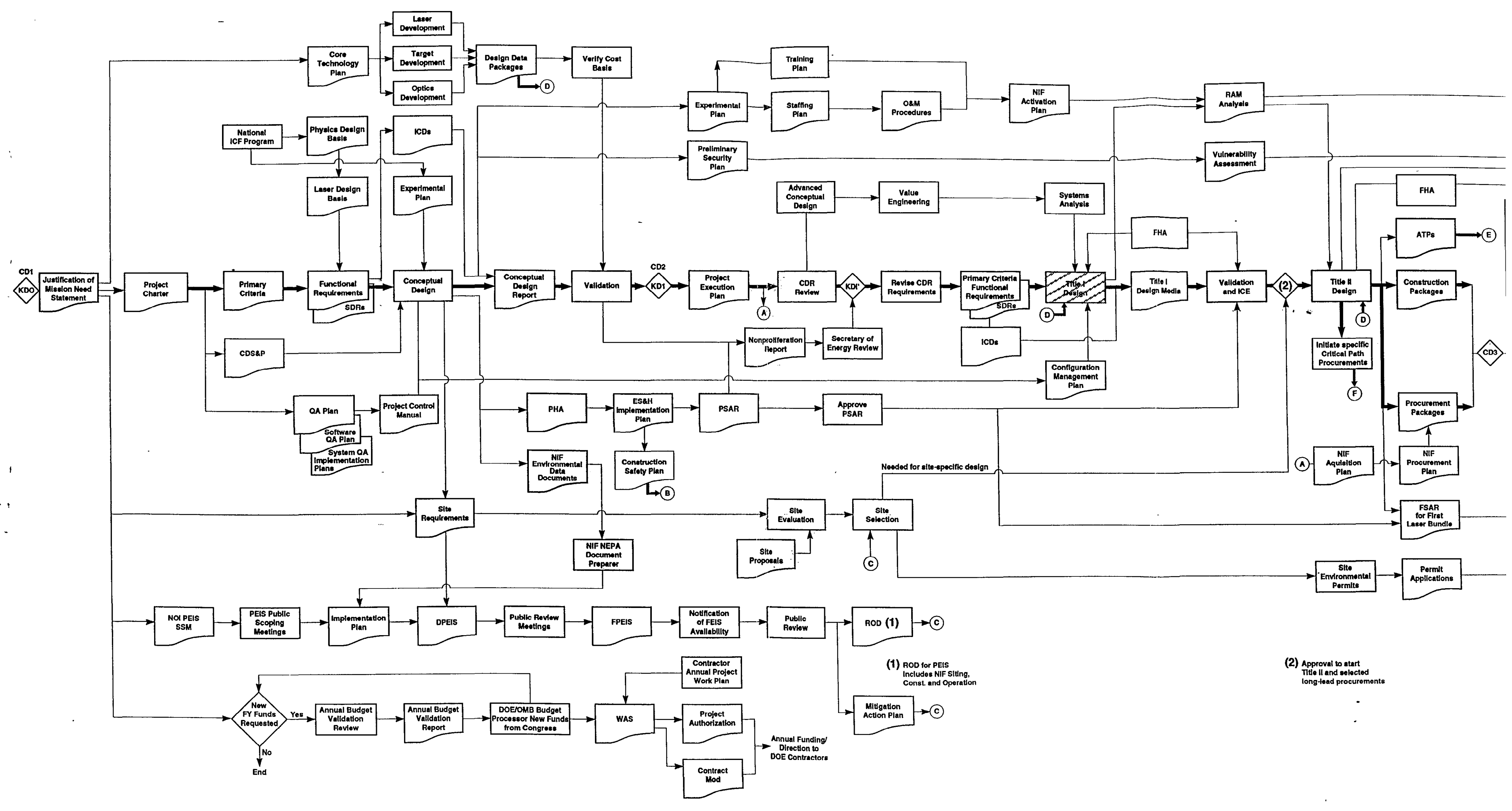




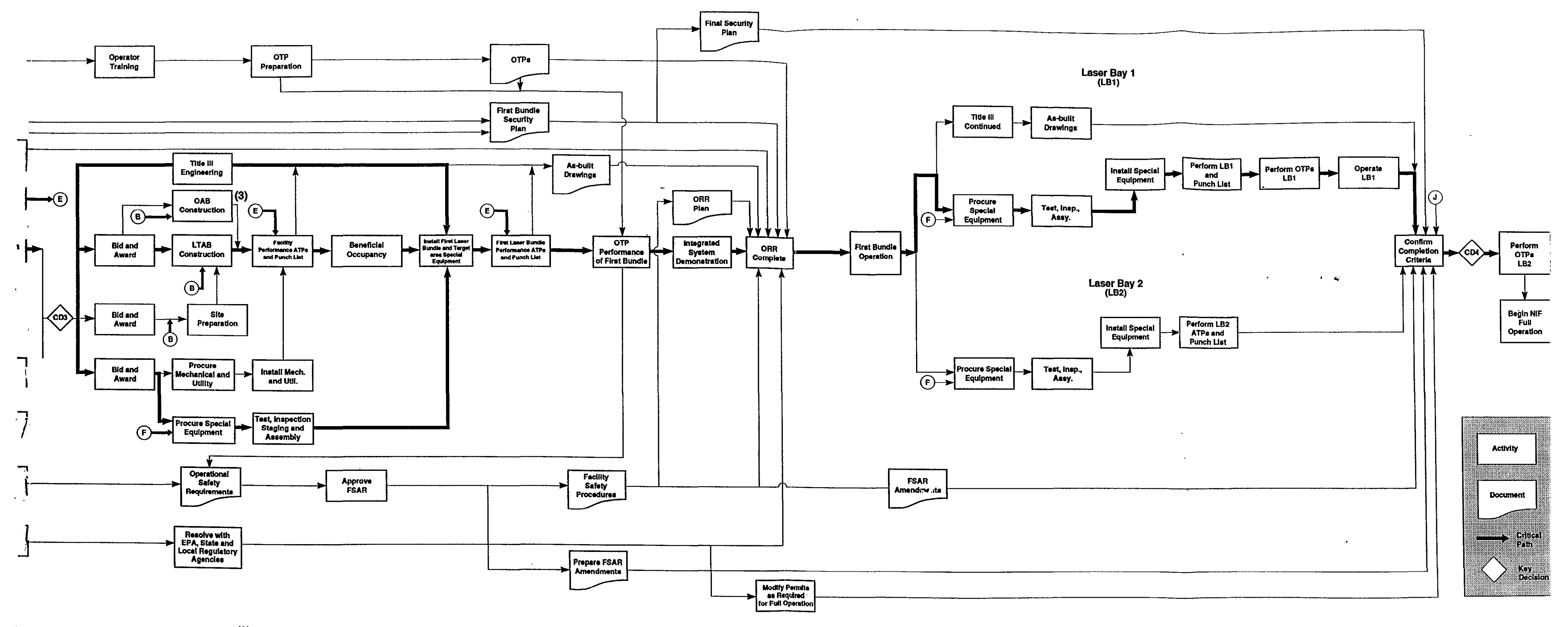

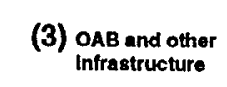

Figure B-1. NIF Project Work Logic Diagran 


\section{Appendix C}

\section{NIF Project Data Sheet}


DEPARTMENT OF ENERGY

FY 1999 OMB BUDGET REQUEST

(Changes from FY 1998 Congressional Budget Request are denoted with a vertical line in left margin.)

WEAPONS ACTIVITIES

(Tabular dollars in thousands. Narrative material in whole dollars.)

Weapons Stockpile Stewardship

Inertial Confinement Fusion

1. Title and Location of Project: National Ignition Facility (NIF)

Lawrence Livermore National Laboratory (LLNL), Livermore, CA

2a. Project No. 96-D-111

2b. Construction Funded

SIGNIFICANT CHANGES

I. None. 


\section{DEPARTMEN F ENERGY}

\section{FY 1999 OMB BUDGET REQUEST}

(Changes from FY 1998 Congressional Budget Request are denoted with a vertical line in left margin.)

WEAPONS ACTIVITIES

(Tabular dollars in thousands. Narrative material in whole dollars.)

Weapons Stockpile Stewardship

Inertial Confinement Fusion

\begin{tabular}{lccc}
\hline 1. Title and Location of Project: & $\begin{array}{c}\text { National Ignition Facility (NIF) } \\
\text { Lawrence Livermore National Laboratory (LLNL), Livermore, CA }\end{array}$ & $\begin{array}{l}\text { 2a. } \\
\text { 2b. }\end{array}$ Project No. 96-D-111 \\
Construction Funded
\end{tabular}

7. Financial Schedule (Federal Funds);

\begin{tabular}{|c|c|c|c|c|}
\hline Fiscal Year & Appropriation & Adjustments & Obligations & Costs \\
\hline Previous & $\$ 0$ & $\$$ & $\$ 0$ & $\$ 0$ \\
\hline 1996 & 37,400 & 0 & 37,400 & 33,990 \\
\hline 1997 & 131,900 & 0 & 131,900 & 103,010 \\
\hline 1998 & 197,800 & 0 & 197,800 & 180,600 \\
\hline 1999 & 284,200 & 0 & 284,200 & 208,300 \\
\hline 2000 & 248,100 & 0 & 248,100 & 199,900 \\
\hline 2001 & 74,100 & 0 & 74,100 & 179,700 \\
\hline 2002 & 65,000 & 0 & 65,000 & 122,000 \\
\hline 2003 & 7,200 & 0 & 7,200 & 18,200 \\
\hline
\end{tabular}




\section{Project Description Justification and Scope}

The Project provides for the design, procurement, construction, assembly, installation, and acceptance testing of the National Ignition Facility (NIF), an experimental inertial confinement fusion facility intended to achieve controlled thermonuclear fusion in the laboratory by imploding a small capsule containing a mixture of the hydrogen isotopes, deuterium and tritium. The NIF will be constructed at the Lawrence Livermore National Laboratory (LLNL), Livermore, California as determined by the Record of Decision made on December 19, 1996, as a part of the Stockpile Stewardship and Management Programmatic Environmental Impact Statement (SSM PEIS).

The mission of the National Inertial Confinement Fusion (ICF) program is to achieve controlled thermonuclear fusion in the laboratory. This program supports the DOE mandate of maintaining nuclear weapons science expertise required for stewardship of the stockpile, testing of nuclear weapons effects, and the development of fusion power by providing a database for inertial fusion ignition. As a key element of the Stockpile Stewardship Program, the NIF is designed to achieve propagating fusion burn and modest (1-10) energy gain within 2-3 years of full operation and to conduct high energy density experiments, both through fusion ignitions and through direct application of the high laser power. This mission was identified in the NIF Justification of Mission Need, which was endorsed by the Secretary of Energy. Identification of target ignition as the next important step in ICF development for both defense and non-defense applications is consistent with the earlier (1990) recommendation of DOE's Fusion Policy Advisory Committee, and the National Academy of Sciences Inertial Fusion Review Group. In 1995, the DOE's Inertial Confinement Fusion Advisory Committee affirmed the program's readiness for an ignition experiment. A review by the JASONs in 1996 affirmed the value of the NIF for stockpile stewardship.

The NIF project supports the DOE mandate to maintain nuclear weapons science expertise required for stewardship of the stockpile. After the United States announcement of a moratorium on underground nuclear tests in 1992, the Department established the Stockpile Stewardship program to ensure the preservation of the core intellectual and technical competencies in nuclear weapons. In addition, as a means of reducing the danger posed by nuclear weapons proliferation, the President announced that the United States would seek a zero yield Comprehensive Test Ban Treaty (CTBT). The treaty was signed on September 24, 1996. One of the six safeguards that defines the terms of the CTBT is the conduct of the Stockpile Stewardship program to ensure the safety and reliability of the stockpile. The NIF is one of the most vital facilities in that program. The NIF will provide the capability to conduct laboratory experiments to address the high energy density and fusion aspects that are so important to both primaries and secondaries in stockpile weapons.

At present, the Nation's computational capabilities and scientific knowledge are inadequate to ascertain all of the performance and safety impacts from changes in the nuclear warhead physics packages due to aging, remanufacturing, or engineering and design alterations. Such changes are inevitable if the warheads in the stockpile are retained well into the next century, as expected. In the past, the impacts of such changes were evaluated through nuclear weapon tests. Without underground tests, we will require better, more accurate computational capabilities to assure the reliability and safety of the nuclear weapons stockpile for the indefinite future.

To achieve the required level of confidence in our predictive capability, it is essential that we have access to near-weapons conditions in laboratory experiments. The importance of nuclear weapons to our national security requires such confidence. For detonation of weapon primaries, that access is provided in part by hydrodynamic testing. For secondaries and for some aspects of primary performance, the NIF will be a principal laboratory experimental physics facility.

The most significant potential commercial application of ICF in the long term is the generation of electric power. Consistent with the recommendations of the Fusion Policy Advisory Committee, the NIF will provide a unique capability to address critical elements of the 
8. Project Description. Justification and Scope (continued)

inertial fusion energy program by exploring moderate gain (1 to 10) target designs, establishing requirements for driver energy and target illumination for high gain targets, and developing materials and technologies useful for civilian inertial fusion power reactors.

The ignition of an inertial fusion capsule in the laboratory will produce extremely high temperatures and densities in matter. Thus, the NIF will also become a unique and valuable laboratory for experiments relevant to a number of areas of basic science and technology.

The NIF is an experimental fusion facility consisting of a laser and target area, and associated assembly and refurbishment capability. The laser will be capable of providing an output pulse with an energy of 1.8 megajoules (MJ) and an output pulse power of 500 terawatts (TW) at a wavelength of 0.35 micrometers $(\mu \mathrm{m})$ and with specified symmetry, beam balance and pulse shape. The NIF design calls for an experimental facility to house a multibeam line, neodymium $(\mathrm{Nd})$ glass laser capable of generating and delivering the pulses to a target chamber. In the target chamber, a positioner would center a target containing fusion fuel, a deuterium-tritium mixture, for each experiment. Diagnostics provided by this project would provide the test data to demonstrate subsystem performance and initial operations.

The NIF experimental facility, titled the Laser and Target Area Building, would provide an optically stable and clean environment. This laser building would be shielded for radiation confinement around the target chamber and will be designed as a radiological, low -hazard facility capable of withstanding the natural phenomena specified for the LLNL site. The baseline facility is for one target chamber, but the design shall not preclude future upgrade for additional target chambers.

The NIF project consists of conventional and special facilities.

- Site and Conventional Facilities include the land improvements (e.g., grading, roads) and utilities (electricity, heating gas, water), as well as the laser building, which has an approximately 20,300 square meters footprint and 38,000 square meters in total area. It is a reinforced concrete and structural steel building that provides the vibration-free, shielded, and clean space for the installation of the laser, target area, and integrated control system. The laser building consists of two laser bays, each $31 \mathrm{~meters}(\mathrm{~m})$ by $135 \mathrm{~m}$ long, and a central target area--a heavily shielded ( $1.8 \mathrm{~m}$ thick concrete) cylinder $32 \mathrm{~m}$ in diameter and $32 \mathrm{~m}$ high. The laser building includes security systems, radioactive confinement and shielding, control rooms, supporting utilities, fire protection, monitoring, and decontamination and waste handling areas. Optics assembly and refurbishment capability is provided for at LLNL by incorporation of an optics assembly area attached to the laser building and minor modifications of other existing site facilities. 
8. Project Description.Justification and Scope (continued)

- Special facilities include the Laser System, Target Area, Integrated Computer Control System, and Optics.

- The laser system is designed to generate and deliver high power optical pulses to the target chamber. The system consists of 192 laser beamlets configured to illuminate the target surface with a specified symmetry, uniformity, and temporal pulse shape. The laser pulse originates in the pulse generation system. This precisely formatted low energy pulse is amplified in the main amplifier. To minimize intensity fluctuation, each beam is passed through a pinhole in a spatial filter on each of the four passes through the amplifier and through a transport spatial filter. The beam transport directs each high power laser beam to an array of ports distributed around the target chamber where the frequency of the laser light is tripled to $0.35 \mu \mathrm{m}$, spatially modulated by phase plates and focused on the target. Systems are provided for automatic control of alignment and the measurement of the power and energy of the beam. Structural support and auxiliary systems provide the stable platform and utilities required.

- The target area includes a $10 \mathrm{~m}$ diameter, low activation (i.e., activated from radiation) aluminum vacuum chamber located in the Target Area of the laser building. Within this chamber, the target will be precisely located. The chamber and building structure provide confinement of radioactivity (e.g., $x$-rays, neutrons, tritium, and activation products). Diagnostics will be arranged around the chamber to demonstrate subsystem performance for project acceptance (TEC) and initial operations (TPC). Structural, utility and other support systems necessary for safe operation and maintenance will also be provided in the Target Area. The target chamber and staging areas will be capable of conducting experiments with cryogenic targets. The Experimental Plan indicates that cryogenic target experiments for ignition will be needed 2-3 years after completion of the project. Therefore, the targets and this cryogenic capability will be supplied by the experiments. The NIF project will make mechanical and electrical provisions necessary to position and align the cryogenic targets within the chamber. The baseline is for indirectly driven targets. An option for future modifications to permit directly driven targets is included in the design.

- The integrated computer control system includes the computer systems (note: no individual computer will cost over $\$ 100,000$ ) required to control the laser and target systems. The system will provide the hardware and software necessary to support NIF operations. Also included is an integrated timing system for experimental control of laser and diagnostic operations. Safety interlocks and access control will also be provided.

- Thousands of optical components will be required for the 192 beamlet NIF. These components include laser glass, lenses, mirrors, polarizers, deuterated potassium dihydrogen phosphate crystals, pulse generation optics, debris shields and windows, and the required optics coatings. Optics includes quality control equipment to receive, inspect, characterize, and refurbish the optical elements. 


\section{Details of Cost Estimate}

\section{Item Cost Total Cost}

a. Design and Management Costs

1. Engineering, design and inspection at approximately 21.9 percent of construction costs (Item c)

2. Construction management at approximately 3.1 percent of construction costs (Item c).

3. Project management at approximately 6.7 percent of construction costs (Item c)

b. Land and land rights

c. Construction costs..

1. Improvements to land

2. Buildings modification .

175,800

3. Site-specific infrastructure

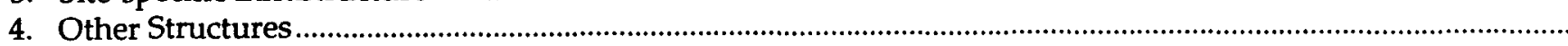

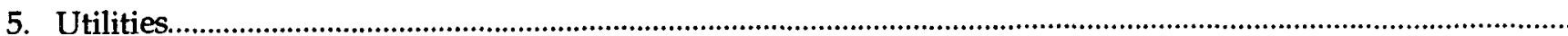

6. Special Facilities 515,700

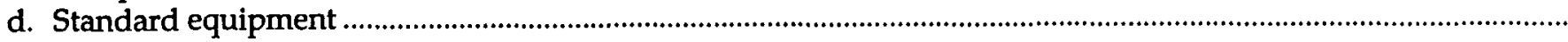

e. Major computer items

f. Removal cost less salvage

g. Design and project liaison, testing, checkout and acceptance

h. Subtotal (a through g)...

i. Contingencies of approximately 15.1 percent of remaining costs at completion of Title I Design .

j. Total line item cost [Section 11.a.1.(a)]

k. LESS: Non-Federal contribution.

1. Net Federal total estimated cost (TEC)

$\begin{array}{r}0 \\ 0 \\ 0 \\ 0 \\ \$ 913,900 \\ 131,800 \\ \$ 1,045,700^{1} \\ 0 \\ \$ 1,045,700 \\ \hline\end{array}$

The cost estimate assumes a project organization and cost distribution consistent with the management requirements appropriate for a DOE Strategic System as outlined in the DOE Order 430.1, Life Cycle Asset Management and the NIF Project Execution Plan. Actual cost distribution will be in conformance with accounting guidelines in place at the time of project execution.

\footnotetext{
1) Based on 100 percent Title I design completion.
} 


\section{Method of Performance}

The NIF Laboratory Project Office (consisting of LLNL, LANL, SNL, and UR/LLE and supported by competitively-selected contracts with Architect Engineering firms, a Construction Manager, equipment and material vendors, and construction firms) will prepare the design, procure equipment and materials, and perform conventional construction, safety, system analysis, and acceptance tests. DOE will maintain oversight and coordination through the Headquarters Office of Inertial Fusion and the National Ignition Facility Project and the field office. DOE conducted the site selection and the NEPA determination. LLNL was selected as the construction site in the Record of Decision made on December 19, 1996. The procurement and installation/test of special equipment will be performed by the NIF Laboratory Project Office. Inspection and Title III engineering contracts for the conventional systems will be competitively awarded. NIF start-up will be conducted by the NIF laboratory operations staff. 


\begin{tabular}{llll}
\hline 1. & and Location of Project: & National Ignition Facility & \\
Lawrence Livermore National La & 2a. Project No. 96-D-111 \\
2b. Construction Funded
\end{tabular}

11. Schedule of Project Funding and Other Related Funding Requirements

a. Total project costs

\section{Prior Years ${ }^{2} / \quad$ FY 1997}

$\underline{F Y 1998} \quad \underline{F Y 1999} \quad \underline{F Y 2000} \quad$ Outyears

$\underline{\text { Total }}$

1. Total facility costs
(a) Line item (Section 9.j.).
$\$ 33,990$
(b) Plant, Engineering and Design (PE\&D)

$\begin{array}{r}0 \\ 0 \\ 0 \\ \hline \$ 33,990\end{array}$
(c) Operating expenses funded equipment
Inventories Total facility costs (Federal and Non-Federal) ....... \$33,990

$\begin{array}{r}\$ 103,010 \\ 0 \\ 0 \\ 0 \\ \hline \$ 103,010\end{array}$

$\begin{array}{r}\$ 180,600 \\ 0 \\ 0 \\ 0 \\ \hline \$ 180,600\end{array}$

$\$ 208,300$ 0

2. Other project costs

(a) R\&D necessary to complete construction ................ $\$ \quad 7,500$

(b) Conceptual design costs.......................................... 12,300

(c) Decontamination and Decommissioning (D\&D) .. 0

(d) NEPA documentation costs ...................................... 2,600

(e) Other project related costs......................................... 14,218

(f) Total other project costs............................................. \$ $\frac{14,6,618}{70,608}$

(g) Total project cost....................................................... \$ 70,608

(h) LESS: Non-Federal contribution .............................. \$

(i) Net Federal total project (TPC).............................. \$ 70,608

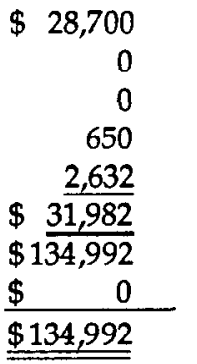

$\$ 52,000$

$\frac{0}{\$ 208,300}$

$\begin{array}{r}\$ 199,900 \\ 0 \\ 0 \\ 0 \\ \hline\end{array}$

$\$ 199,900$

$\$ 12,550$

Note: Budget Authority (BA) requirements

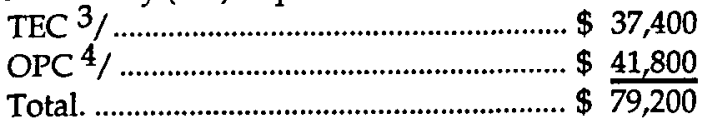

$\$ 131,900$
$\$ \frac{59,200}{\$ 191,100}$

0

550

2,450

$\$ 55,000$

$\$ 235,600$

$\$ \quad 12,550$

0

400

2,550

$\$ \frac{15,500}{23,800}$

$\$ 223,800$

$\$ 235,600$

$\$ 223,800$

$\$ 197,800$

$\$ 31,300$

$\$ 229,100$

$\$ 284,200$

$\$ 6,800$

$\$ 29 \overline{1,000}$

\begin{tabular}{lr} 
& 150 \\
& 0 \\
& 0 \\
& 200 \\
& $\frac{5,600}{5,950}$ \\
$\$$ & 205,850 \\
$\$$ & 0 \\
\hline$\$ 205,850$ \\
\hline
\end{tabular}

$\$ 2 \overline{58,000}$

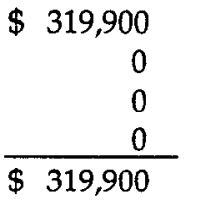

$\$ 1,045,700$

\begin{tabular}{lr} 
& 0 \\
& 0 \\
& 0 \\
& 200 \\
& $\underline{7,950}$ \\
$\$$ & $\underline{8,150}$ \\
$\$$ & 328,050 \\
$\$$ & 0 \\
\hline$\$$ & $\underline{328,050}$
\end{tabular}

$\$ 1,045,700$

100,900

12,300

0

4,600

35,400

$\$ 153,200$

$\$ 1,198,900$

$\$ \quad 0$

$\$ 146,300$

$\$ 1,045,700$

$\$ 4,100$

$\$ 153,200$

b. Related annual costs (estimated life of project-30 years)

1. Facility operating costs..............................

3. Programmatic operating expenses directly related to the facilit

4. Capital equipment not related to construction, but related to the programmatic effort in the facility

5. GPP or other construction related to programmatic effort in the facility.

$\$ 15 \overline{0,400}$

$\$ 1, \overline{198,900}$

6. Utility costs

7. Other costs

Total related annual funding (in FY 1999 dollars)

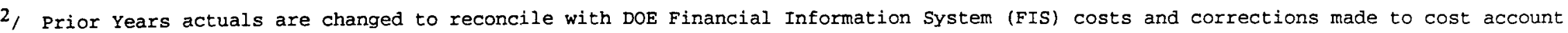
WBS assignment.

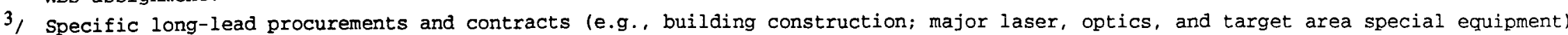
require $B A$ in advance of costs.

4/ Specific long-lead procurements and contracts (e.g., optics facilitization) require BA in advance of costs.

5) This primary experimental operating expense will be included in the base Inertial confinement Fusion Program budget. 


\section{Narrative Explanation of Total Project Funding and Other Related Funding Requirements}

a. Total project costs

1. Total facility costs

(a) Line item - Narrative not required.

(b) PE\&D -- None.

(c) Operating expense funded equipment -- None.

(d) Inventories -- None.

2. Other project costs

(a) R\&D necessary to complete construction -- Costs include optics vendor facilitization $(\$ 73,200,000)$ and optics quality assurance $(\$ 27,700,000)$.

(b) Conceptual design and engineering studies -- Includes the original conceptual design report completed in FY 1994 (\$12,000,000) and the conceptual design activities for the optical assembly and refurbishment capability and site infrastructure $(\$ 300,000)$.

(c) Decontamination and decommissioning (D\&D) -- None.

(d) NEPA documentation - Preparation includes the NIF portion of the Stockpile Stewardship and Management Programmatic Environmental Impact Statement $(\$ 2,600,000)$ and environmental monitoring and permits $(\$ 2,000,000)$.

(e) Other project related costs - Engineering studies (including advanced conceptual design) of project options ( $\$ 5,800,000)$; assurances, safety analysis, and integration $(\$ 9,300,000)$; start-up planning, management, training, and staffing $(\$ 8,600,000)$; procedure preparation $(\$ 1,500,000)$; operating spares $(\$ 600,000)$; start-up $(\$ 7,700,000)$; and ORR $(\$ 1,900,000)$.

b. Related annual costs

1. Facility operating costs -- Includes operator labor, engineering support and materials for upgrades and modifications, and consumables for operation of special equipment.

2. Facility maintenance and repair costs - Includes cost of labor, engineering support, and consumables for special equipment maintenance and refurbishment, including optics. Also includes maintenance for the laser building and support buildings.

3. The current NOVA experimental program, including LLNL, LANL, SNL, and General Atomics, is approximately $\$ 40,100,000$ annually. Based on use of complex cryogenic targets, increased diagnostics support, and higher levels of three dimensional physics modeling, the annual direct NIF experimental program costs are estimated at $\$ 59,600,000$. Additional program costs will be associated with use of the facility.

4. Fabrication accounts, procurements, such as small lasers and some laser parts, Computer-Aided Design systems, etc. to support upgrades.

5. Minor additions and modifications to the facility related to programmatic effort.

6. Electricity only. Gas, sewer, water, etc. are paid out of the General and Administrative budget.

7. Nitrogen and argon for laser and transport beam tubes, stock inventory, and procurement support. 
13. Design and Construction of Federal Facilities

All DOE facilities are designed and constructed in accordance with applicable Public Laws, Executive Orders, OMB Circulars, Federal Property Management Regulations, and DOE Orders. The total estimated cost of the project includes the cost of measures necessary to assure compliance with Executive Order 12088, "Federal Compliance with Pollution Control Standards"; section 19 of the Occupational Safety and Health Act of 1970, the provisions of Executive Order 12196, and the related Safety and Health provisions for Federal Employees (CFR Title 29, Chapter XVII, Part 1960); and the Architectural Barriers Act, Public Law 90-480, and implementing instructions in 41 CFR 101-19.6. The project will be located in an area not subject to flooding determined in accordance with Executive Order 11988. DOE has reviewed the GSA inventory of Federal Scientific laboratories and found insufficient space available, as reported by the GSA inventory.

\section{Supplemetary Project Data for Facility Utilization}

The NIF will provide new space and capacity. A Facility Use Plan has been prepared. 


\section{Appendix D}

\section{NIF Project Baseline Costs}

NIF Annual Financial Schedule (Escalated \$M)

\begin{tabular}{|c|c|c|c|c|c|c|c|c|c|c|c|c|c|}
\hline & FY93 & FY94 & FY95 & FY96 & FY97 & FY98 & FY99 & FY00 & FY01 & FY02 & FY03 & Total \\
\hline \hline Total Estimated Cost & & & & & & & & & & & & \\
\hline BO & & & & 34.0 & 103.0 & 180.6 & 208.3 & 199.9 & 179.7 & 122.0 & 18.2 & $1,045.7$ \\
\hline BA & & & & 37.4 & 131.9 & 197.8 & 284.2 & 248.1 & 74.1 & 65.0 & 7.2 & $1,045.7$ \\
\hline Other Project Cost & & & & & & & & & & & & \\
\hline BO & 2.6 & 9.6 & 5.3 & 19.1 & 32.0 & 55.0 & 15.5 & 5.8 & 5.9 & 1.2 & 1.2 & 153.2 \\
\hline BA & 6.0 & 6.2 & 6.0 & 23.6 & 59.2 & 31.3 & 6.8 & 10.0 & 1.8 & 1.4 & 0.9 & 153.2 \\
\hline Total Project Cost & & & & & & & & & & & & \\
\hline BO & 2.6 & 9.6 & 5.3 & 53.1 & 135.0 & 235.6 & 223.8 & 205.7 & 185.6 & 123.2 & 19.4 & $1,198.9$ \\
\hline BA & 6.0 & 6.2 & 6.0 & 61.0 & 191.1 & 229.1 & 291.0 & 258.1 & 75.9 & 66.4 & 8.1 & $1,198.9$ \\
\hline
\end{tabular}

NIF Annual Cost Plan at WBS Level 2 (Escalated \$M)

\begin{tabular}{|l|r|r|r|r|r|r|r|r|r|r|r|r|r|}
\hline & WBS & FY93 & FY94 & FY95 & FY96 & FY97 & FY98 & FY99 & FY00 & FY01 & FY02 & FY03 & Total \\
\hline Total Estimated Cost & & & & & & & & & & & & & \\
\hline Project Office & 1.1 & & & & 10.1 & 14.8 & 13.9 & 8.7 & 7.7 & 6.3 & 3.7 & 1.5 & 66.7 \\
\hline Site \& Conventional Facilities & 1.2 & & & & 6.8 & 24.5 & 88.1 & 53.2 & 28.5 & 12.6 & & & 213.7 \\
\hline Laser Systems & 1.3 & & & & 3.8 & 13.5 & 12.9 & 29.7 & 39.5 & 56.1 & 44.2 & 4.8 & 204.5 \\
\hline Beam Transport System & 1.4 & & & & 3.5 & 11.8 & 10.8 & 40.6 & 17.7 & 6.9 & 0.4 & 0.3 & 92.0 \\
\hline Integrated Computer Control & 1.5 & & & & 2.0 & 3.2 & 3.1 & 3.7 & 4.0 & 3.7 & 1.4 & 0.5 & 21.6 \\
\hline Optical Components & 1.6 & & & & 1.1 & 1.5 & 5.5 & 14.5 & 34.7 & 43.5 & 41.1 & 4.6 & 146.5 \\
\hline Laser Control & 1.7 & & & & 2.4 & 3.7 & 5.6 & 11.5 & 15.6 & 13.4 & 14.4 & 5.4 & 72.0 \\
\hline Target Experimental System & 1.8 & & & & 4.3 & 8.4 & 9.0 & 11.3 & 21.5 & 11.4 & 1.9 & 0.2 & 68.0 \\
\hline Ops Special Equip. & 1.9 & & & & - & 4.8 & 6.7 & 7.7 & 4.7 & 4.5 & 0.4 & 0.1 & 28.9 \\
\hline Contingency & & & & & - & 16.8 & 25.0 & 27.4 & 26.0 & 21.3 & 14.5 & 0.8 & 131.8 \\
\hline Total PACE Funded & & & & & 34.0 & 103.0 & 180.6 & 208.3 & 199.9 & 179.7 & 122.0 & 18.2 & $1,045.7$ \\
\hline & & & & & & & & & & & & & \\
\hline Other Project Cost & & & & & & & & & & & & & \\
\hline Startup Activities & 1.10 & & & & 1.0 & 1.8 & 2.0 & 1.9 & 5.3 & 5.6 & 1.1 & 1.2 & 19.9 \\
\hline ES\&H/Supporting R\&D & 1.11 & 2.6 & 9.6 & 5.3 & 18.1 & 30.2 & 53.0 & 13.6 & 0.5 & 0.3 & 0.1 & - & 133.3 \\
\hline Total OPEX funded & & 2.6 & 9.6 & 5.3 & 19.1 & 32.0 & 55.0 & 15.5 & 5.8 & 5.9 & 1.2 & 1.2 & 153.2 \\
\hline & & & & & & & & & & & & & \\
\hline TOTAL PROJECT COST & & 2.6 & 9.6 & 5.3 & 53.1 & 135.0 & 235.6 & 223.8 & 205.7 & 185.6. & 123.2 & 19.4 & $1,198.9$ \\
\hline
\end{tabular}




\section{Appendix E}

\section{NIF Project Integrated Schedule, Major Milestones and Critical Decisions, and NIF Project Documents}

This appendix contains the NIF Summary Integrated Project Schedule (Figure E-1), the major Project Milestones and Critical Decision Points (Table E-1), and NIF Project Documents (Table E-2).

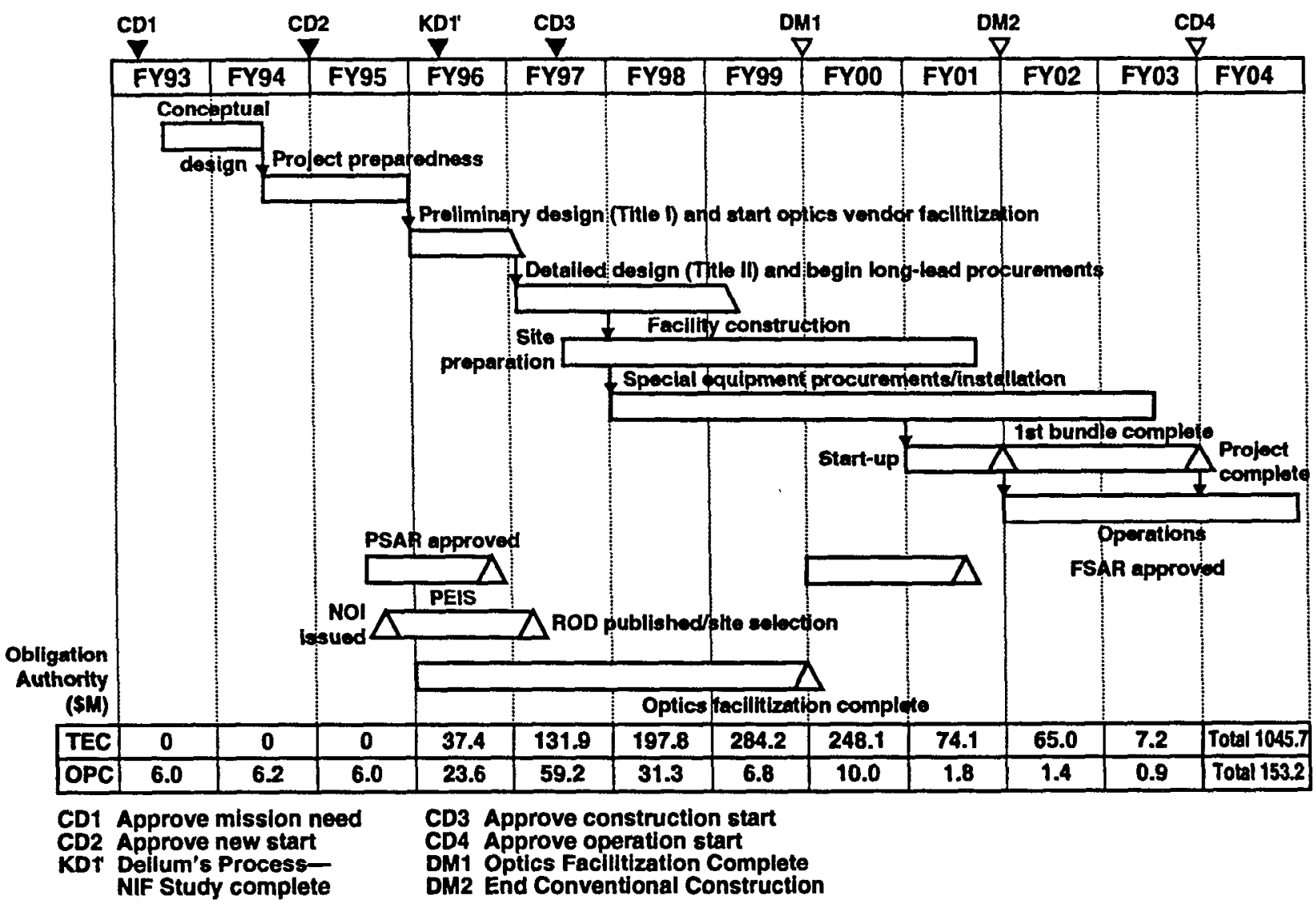

40-00-0105-0260XKpb01

Figure E-1. NIF Summary Integrated Project Schedule. 
Table E-1. NIF Project Major Milestones and Critical Decision Points.

\begin{tabular}{|l|c|c|c|c|c|c|}
\hline \multicolumn{1}{|c|}{ Milestones } & $\begin{array}{c}\text { DOE } \\
\text { DOE } \\
\text { Acquisition } \\
\text { Executive } \\
\text { Level 0 }\end{array}$ & $\begin{array}{c}\text { Fusion and } \\
\text { the NIF } \\
\text { Project } \\
\text { Level 1 }\end{array}$ & $\begin{array}{c}\text { NIF DOE } \\
\text { Field } \\
\text { Office } \\
\text { Level 2 }\end{array}$ & $\begin{array}{c}\text { NIF } \\
\text { Projaject } \\
\text { Office } \\
\text { Level 3 }\end{array}$ & $\begin{array}{c}\text { Date } \\
\text { Planned }\end{array}$ & $\begin{array}{c}\text { Date } \\
\text { Actual }\end{array}$ \\
\hline Approval of Mission Need (CD1) & $\mathrm{X}$ & & & & Jan 1993 & Jan 1993 \\
\hline CDR Complete & & & & $\mathrm{X}$ & May 1994 & May 1994 \\
\hline Approval of New Start (CD2) & $\mathrm{X}$ & & & & Oct 1994 & Oct 1994 \\
\hline Notice of Intent Issued & & $\mathrm{X}$ & & & Jun 1995 & Jun 1995 \\
\hline KD1' Dellums Process Complete & $\mathrm{X}$ & & & & Dec 1995 & Dec 1995 \\
\hline Architect/Engineer Contracted & & & & $\mathrm{X}$ & Dec 1995 & Dec 1995 \\
\hline Title I Initiated & & & & $\mathrm{X}$ & Jan 1996 & Jan 1996 \\
\hline Construction Manager Contracted & & & & $\mathrm{X}$ & May 1996 & May 1996 \\
\hline PSAR DOE Concurence* & & & $\mathrm{X}$ & & Aug 1996 & Aug 1996 \\
\hline PSAR Approved* & & & & $\mathrm{X}$ & Sep 1996 & Sep 1996 \\
\hline NEPA Record of Decision & $\mathrm{X}$ & & & & Sep 1996 & Dec 1996 \\
\hline Approval to Initiate Title II Design & & & $\mathrm{X}$ & & Sep 1996 & Nov 1996 \\
\hline $\begin{array}{l}\text { Approval to Initiate Long-Lead } \\
\text { Procurement }\end{array}$ & & & $\mathrm{X}$ & & Sep 1996 & Nov 1996 \\
\hline Approval to Initiate Construction \\
(CD3)
\end{tabular}


Table E-2. NIF Project Documents.

\begin{tabular}{|c|c|c|c|c|c|c|c|c|}
\hline \multirow[b]{2}{*}{ Document } & \multirow[b]{2}{*}{ Freq. } & \multicolumn{7}{|c|}{ Responsibilities } \\
\hline & & $\mathbf{A E}$ & $\mathbf{D P}$ & EH & FM & NDFO* & NLPO $^{* *}$ & NEPA $^{* * *}$ \\
\hline Justification of Mission Need & o & $\mathrm{A}$ & $\mathrm{P}$ & - & - & 二 & 二 & - \\
\hline Project Data Sheet & $\mathbf{a}$ & - & $\mathrm{A}$ & - & $\mathbf{R}$ & $\mathbf{R}$ & $\mathrm{P}$ & - \\
\hline Project Charter & 0 & - & $\mathrm{P}, \mathrm{A}$ & - & - & $I$ & $\mathrm{I}$ & - \\
\hline Project Execution Plan & $\mathrm{n}$ & - & $\mathrm{A}$ & - & - & $\mathrm{P}, \mathrm{A}$ & $\mathrm{P}, \mathrm{A}$ & - \\
\hline Primary Criteria & $\mathrm{n}$ & - & $\mathrm{A}$ & - & - & $I$ & $\mathbf{P}$ & - \\
\hline Functional Requirements & $\mathbf{n}$ & - & $\mathrm{I}$ & - & - & A & $\mathrm{P}$ & - \\
\hline System Design Requirements & $\mathbf{n}$ & 二 & - & - & - & $\mathrm{I}$ & $\mathrm{P}, \mathrm{A}$ & - \\
\hline Interface Control Documents & $\mathrm{n}$ & - & - & - & - & $I$ & $\mathrm{P}, \mathrm{A}$ & - \\
\hline Preliminary Hazards Analysis & 0 & - & C & - & - & $\mathrm{C}$ & $\mathrm{P}, \mathrm{A}$ & $=$ \\
\hline Quality Assurance Plan & $\mathrm{n}$ & - & I & - & - & C & $\mathrm{P}, \mathrm{A}$ & - \\
\hline Conceptual Design Report & 0 & - & $\mathbf{R}$ & - & - & $\mathbf{R}$ & $\mathrm{P}, \mathrm{A}$ & - \\
\hline Environmental Permits & $\mathbf{n}$ & - & - & - & - & $\mathrm{C}$ & $\mathbf{P}$ & - \\
\hline NEPA (PEIS/ROD) & o & A & $\mathbf{R}$ & C & - & In & In & $P$ \\
\hline Prelim. Safety Analysis Report & 0 & - & C & - & - & $\mathrm{C}$ & $\mathrm{P}, \mathrm{A}$ & - \\
\hline ES\&H Plan & $\mathbf{n}$ & - & $I$ & - & - & $\mathrm{C}$ & $\mathrm{P}, \mathrm{A}$ & - \\
\hline Security Plan & $\mathbf{n}$ & - & 1 & $=$ & - & $\mathrm{C}$ & $\mathrm{P}, \mathrm{A}$ & - \\
\hline Quality Assurance Audit & $\mathrm{n}$ & $=$ & $I$ & - & - & $\mathbf{P}$ & $\mathrm{I}$ & - \\
\hline Construction Completion Report & $\mathbf{0}$ & $=$ & I & - & - & A & $\mathbf{P}$ & - \\
\hline Project Control Manual & $\mathrm{n}$ & 二 & $\mathrm{I}$ & $=$ & - & $\mathrm{C}$ & $\mathrm{P}, \mathrm{A}$ & 二 \\
\hline Final Safety Analysis Report & 0 & - & $\mathrm{C}$ & - & - & C & $\mathrm{P}, \mathrm{A}$ & - \\
\hline Operational Test Procedures & $\mathrm{n}$ & $-\mathrm{C}$ & - & - & A & $\mathrm{P}$ & - & \\
\hline Operational Readiness Report & 0 & - & $\mathrm{I}$ & - & 二 & $\mathrm{C}$ & $\mathrm{P}, \mathrm{A}$ & $=$ \\
\hline ORR Validation Report & 0 & - & $\mathrm{C}$ & - & - & $\mathrm{P}, \mathrm{A}$ & $I$ & $=$ \\
\hline Annual Budget Validation Report & a & - & $\mathbf{R}$ & - & $\mathbf{P}, \mathbf{A}$ & $\mathbf{R}$ & $\mathrm{R}$ & - \\
\hline Unusual Occurrence Report & $\mathrm{n}$ & $=$ & $I$ & $I$ & - & I & $\mathrm{P}, \mathrm{A}$ & - \\
\hline Configuration Management Plan & $\mathrm{n}$ & - & $I$ & - & - & $\mathrm{C}$ & $\mathrm{P}, \mathrm{A}$ & - \\
\hline Monthly Status Report & $\mathbf{m}$ & - & I & - & - & I & $\mathrm{P}$ & - \\
\hline Quarterly Status Report & $\mathrm{q}$ & - & $\mathrm{I}$ & - & 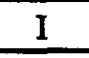 & $\mathbf{P}$ & $\mathbf{P}$ & - \\
\hline $\begin{array}{l}\text { * NIF DOE Field Office } \\
\text { N* NIF Laboratory Project Office } \\
\text { *** NEPA preparer } \\
\text { **** Approval by EPA, Regional Air } \\
\text { Frequency Key: } a=\text { annual, } n=\text { "as- } n\end{array}$ & $\begin{array}{l}\text { ity } \\
d^{\prime \prime}=\end{array}$ & cts & & 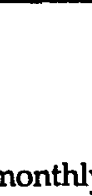 & & & & \\
\hline
\end{tabular}




\section{Appendix F}

\section{Reporting Requirements}

Table F-1 provides an overview of the reporting requirements applicable to the NIF Project. 
Table F-1. Project Reporting Requirements.

\begin{tabular}{|c|c|c|c|c|c|c|}
\hline $\begin{array}{c}\text { Project reports to } \\
\text { DOE management } \\
\text { levels }\end{array}$ & Financial & Cost & Schedule & Technical & Work Execution & Accomplishments and Issues \\
\hline 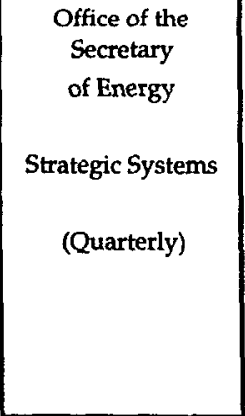 & \multicolumn{5}{|c|}{$\begin{array}{l}\text { Current status and evaluation of schedule, work execution, financial, and cost conditions as } \\
\text { needed to describe current or potential problems pertaining to Secretary of Energy Level } \\
\text { baselines; i.e , schedule milestones, total cost estimate, or overall Strategic System mission }\end{array}$} & $\begin{array}{l}\text { Top level } \\
\text { issues/accomplishments on } \\
\text { Strategic Systems include } \\
\text { potential or imminent baseline } \\
\text { changes that require } \\
\text { Secretarial approval or } \\
\text { attention Departmental } \\
\text { strategic topics include } \\
\text { external stakeholders, } \\
\text { litigation, environmental, } \\
\text { safety, health, procurement, } \\
\text { human resources, and risk } \\
\text { level changes }\end{array}$ \\
\hline $\begin{array}{c}\text { Office of the } \\
\text { National Ignition } \\
\text { Facility (Quarterly) }\end{array}$ & $\begin{array}{l}\text { Current fiscal } \\
\text { year and } \\
\text { cumulative to- } \\
\text { date amounts } \\
\text { for budget } \\
\text { authority } \\
\text { allotted and } \\
\text { obligated funds. }\end{array}$ & $\begin{array}{l}\text { At the total } \\
\text { project level of } \\
\text { detail, current } \\
\text { fiscal ycar and } \\
\text { cumulative to- } \\
\text { date planned } \\
\text { and incurred } \\
\text { costs, annual } \\
\text { and total project } \\
\text { estimates at } \\
\text { completion. }\end{array}$ & $\begin{array}{l}\text { Current status } \\
\text { on } \\
\text { Headquarters } \\
\text { program levcl } \\
\text { schedule } \\
\text { milestones, } \\
\text { baseline or } \\
\text { planned dates } \\
\text { actual/forecast } \\
\text { dates. }\end{array}$ & $\begin{array}{l}\text { Current status } \\
\text { on } \\
\text { Headquarters } \\
\text { program level } \\
\text { technical } \\
\text { objectives; i.e, } \\
\text { requirements as } \\
\text { described in an } \\
\text { approved } \\
\text { project } \\
\text { execution plan } \\
\text { Current status } \\
\text { compares the } \\
\text { technical } \\
\text { requirement } \\
\text { with a } \\
\text { determination of } \\
\text { progress and } \\
\text { problems } \\
\text { toward meeting } \\
\text { the technical } \\
\text { requirement. }\end{array}$ & $\begin{array}{l}\text { Current status } \\
\text { of work scope } \\
\text { toward } \\
\text { accomplishment } \\
\text { of Headquarters } \\
\text { program level } \\
\text { technical } \\
\text { objectives of a } \\
\text { project } \\
\text { Evaluation of } \\
\text { schedule, } \\
\text { technical, } \\
\text { financial and } \\
\text { cost progress } \\
\text { and problems } \\
\text { including cause } \\
\text { of problems, } \\
\text { impacts, and } \\
\text { corrective } \\
\text { actions. }\end{array}$ & $\begin{array}{l}\text { Significant accomplishments } \\
\text { relating to project execution. } \\
\text { Project related issues needing } \\
\text { Headquarters office(s) } \\
\text { assistance }\end{array}$ \\
\hline $\begin{array}{l}\text { NIF DOE Field } \\
\text { Office } \\
\text { (Monthly) }\end{array}$ & $\begin{array}{l}\text { Current fiscal } \\
\text { year and } \\
\text { cumulative to- } \\
\text { date amounts } \\
\text { for budget } \\
\text { authority } \\
\text { allotted and } \\
\text { obligated funds } \\
\text { at WBS Level } 2 \\
\text { and selected } \\
\text { Level } 3 .\end{array}$ & $\begin{array}{l}\text { Current fiscal } \\
\text { year cumulative } \\
\text { to-date planned } \\
\text { and incurred } \\
\text { costs and annual } \\
\text { project estimates } \\
\text { at completion at } \\
\text { WBS Level } 2 \\
\text { and selected } \\
\text { Level } 3\end{array}$ & $\begin{array}{l}\text { Status of } \\
\text { schedule } \\
\text { milestones, } \\
\text { baseline or } \\
\text { planned dates } \\
\text { actual/forecast } \\
\text { dates at WBS } \\
\text { Level } 2 \text { and } \\
\text { selected Level } 3 .\end{array}$ & $\begin{array}{l}\text { Status of } \\
\text { technical } \\
\text { objectives at } \\
\text { WBS Level } 2 \\
\text { and selected } \\
\text { Level 3; i.e., } \\
\text { requirements as } \\
\text { described in an } \\
\text { approved } \\
\text { project } \\
\text { execution plan } \\
\text { Current status } \\
\text { compares the } \\
\text { technical } \\
\text { requirement } \\
\text { with a } \\
\text { determination of } \\
\text { progress and } \\
\text { problems } \\
\text { toward meeting } \\
\text { the technical } \\
\text { requirement. }\end{array}$ & $\begin{array}{l}\text { Evaluation of } \\
\text { schedule, } \\
\text { technical. } \\
\text { financial and } \\
\text { cost progress } \\
\text { and problems } \\
\text { including cause } \\
\text { of problems, } \\
\text { impacts, and } \\
\text { corrective } \\
\text { actions. }\end{array}$ & $\begin{array}{l}\text { Participants shall report any } \\
\text { issues that may need } \\
\text { Departmental attention } \\
\text { relating to execution of project } \\
\text { work }\end{array}$ \\
\hline
\end{tabular}

* Departmental project reporting requirements necessary for normal project oversight and management actions Project reporting requirements are intended for formal communication in written form They are not intended to take the place of routine communication described in Chapter 3 or verbal status presentations Need for project reports beyond those in this table shall require justification and agreement between NIF Project participants and NIF DOE Project Management 


\section{Appendix G}

\section{Key Decision 1 (Critical Decision 2) Approval Letter,} October 1994 
The Secretary of Energy

Wastington, DC 20585

MEMORANDUM FOR THE SECRETARY

THROUGH: Charles B. Curtis Under Secretary

FROM: Victor H. Reis

SUBJECT: ACTION: Approve Key Decision One for the National Ignition Facility

Since the May 24, 1994, Energy Systems Advisory Board meeting on the National Ignition Facility, the Department has conducted a wide ranging review of issues and concerns associated with prcceeding to the next stage of development of the facility. The issues examined in this context include concerns about the impact of the facility on U.S. nonproliferation goals; contributions of the project to stockpile stewardship efforts and other science. technology and energy objectives of the Department; and environmental, safety, health and budgetary considerations. Many of these issues, most notably the concern that construction of the facility may hinder U.S. nonproliferation objectives, have also been articulated by various individuals, non-governmental organizations, and members of Congress.

The Department concurs that the issues identified above must be carefuldy examined and thoroughly debated prior to a decision to proceed with construction of the facility. To that end. the Department has endorsed an ongoing process of andysis and dialogue as proposed by the Chairman of the House Armed Services Committee, Congressman Ron Dellums, to satisfy concerns about outstanding issues. Specifically, the Dellums process will consist of the following elements:

(1) if a positive Key Decision One lauthorizing preliminary designl is taken, the Department agrees to establish a new milestone -- a Key Decision "One Prime" -- prior to making Key Decision Two (authorizing detailed design). The principal focus of Key Decision One Prime would be to resolve the question of whether or not the National Ignition Facility will aid or hinder our nonproliferation efforts;

(2) an assessment that the mission and purpose of the facility remain timely and relevant:

(3) comprehensive stakeholder participation on issues of concern, especially nonproliferation; and 
(4) coordination with other agencies of the U.S. government necessary for carrying out the steps agreed to above.

The Department rook the first step in implementation of this process through a workshop on the National Ignition Facility on september B, 1994, with representatives of Federal agencies. national laboratories, contractors, non-governmental organizations and advisory groupe.

Besed upon cereful consideration of information and viewpoints received to date, and subject to the conditions and requirements of the Deliums process, we conclude that it is appropriate to approve Key Decision One at this time. Approval of Key Decision one will support the initiation of the National Environmental Policy Act process, as well as the establishment of a budget line item for fiscal year 1996 to support preliminary design work such as engineering studies, preliminary drawings, preliminary cost estimates and project scheduling.

The following assessments support the conclusion to approve Key Decision one at this time:

\section{Missions}

The National Ignition Facility has the potential to contribute oignificantly in the following mission areas:

(1) Nuclear weapons physics: In the absence of underground testing, the National Ignition Facility would be a critical tool for the Department's Science-Based Stockpile stewardship program. It would play an important role in maintaining the continued safety and reliability of the stockpile by creating experimental conditions that approach certain aspects of nuclear weapons physics. In particular. this experimental capability would allow nuclear weapons scientists to assess stockpile problems, verify computational tools, and increase their understanding of weapons physics.

(2) Inertial fusion eneray: The National Ignition Facility would represent the scientific culmination of more than 30 years of research in inertial confinement fusion. This type of fusion concept focuses laser or particle beams on spherical targets causing them to implode, creating high temperatures and pressures necessary for these targets to burn. With the National Ignition Facility. Bcientists plan to achieve ignition (self-heating of the fuel) and fuel burn (more fusion energy produced than laser energy deposited) in the laboratory for the first time. Such an achievement could be an important step toward the development of fusion energy. The recent declassification of work in the inertial confinement fusion program would enable international 
cooperation on experiments at the National Ignition Facility.

(3). Science, technology, and other applications: The National Ignition Facility would be a "magnet" facility, attracting world-class scientists and engineers to work on problems of major importance to society: The ability to probe experimental conditions similar to those at the center of the sun and the stars would accelerate progress in basic sciences such as stellar physics and cosmology. In addition, as the world's largest precision optical instrument, the project would spur industrial capabilities, technologies, and commercial applications.

Cost and Schedule

The facility would take approximately seven years to design and build (fiscal years 1996 through 2002). with the total project cost estimated at $\$ 900 \mathrm{milli}$ on over the seven year period (in Eiscal year 1995 dollars). The annual operating cost is expected to be about $\$ 60$ million. The total experimental operating lifetime of the facility is projected to be 15 years, and cost $\$ 900$ million. Decommissioning and decontamination costs are estimated at $\$ 35$ million. This results in a life-cycle cost estimate of about $\$ 1.8$ billion.

Nonproliferation

Concerns have been expressed about the potential for the National Ignition Facility to undermine U.S. nonproliferation goals. In particular, some have argued that research at the facility would allow the $U$. S. to continue to design and develop advanced new nuclear weapons concepts, thereby circumventing the prohibitions of a Comprehensive Test Ban Treaty. Others are concerned that access to the technologies or research data of the National Ignition Facility by non-nuclear weapon states could lead to horizontal proliferation. On the other hand, because of its contribution to the maintenance of a safe and reliable nuclear stockpile, the National Ignition Facility might further $U . S$. nonproliferation goals by speeding acceptance of a Comprehensive Test Ban by nuclear weapons states.

The Department believes that a policy of international collaboration and transparency for future experimentation at the facility could help dispel fears about a secret advanced U.S. weapons program. and thus assuage many of the nonproliferation concerns. The Department will further explore this approach of openness for the facility, and will resolve the broader range of nonproliferation issues within the Key Decision One Prime process. 


\section{Safety and Environmental Analysis}

The Department has completed a preliminary hazards analysis on the National Ignition Facility followed by safety. environmental. radiarion protection, quality assurance, and decontamination and decommissioning assessments. The facility has been classified by the Department to be a low hazard, nonnuclear facility. The project will be reviewed in accordance with the National Environmental Policy Act to evaluate the safety and environmental impacts from siting, construction and operation of the facility.

\section{siting}

The National Environmental policy Act requires that any preference related to the siting of a facility be stated by the Department. Given the resident technical expertise and existing infrastructure at Lawrence Livermore National Laboratory, we believe that Livermore is preferable at this time to other candidate sites. Accordingly, we would recommend that you announce the Departmental preference for Livermore if Key Decision One is epproved.

\section{National Environmental Policy Act Process}

Approval of Key Decision One obligates the Department to initiate the process of environmental review required under the National Environmental Policy Act. The Department intends to initiate a programutic environmental impact statement on stockpile Stewardship and Management as a replacement to the now outdated programmatic EIS for reconfiguration. Since the National Ignition Facility. would be an important element of the stockpile stewardship.program, we believe that the environmental impact work on the proposed National Ignition Facility should occur within the larger framework of the programmatic environmental impact statement for stockpile stewardship.

\section{Recommendation}

- Approve Key Decision One. which will: (1)initiate the National Envirommental Policy Act process for the facility; and (2)establish a line item in the fiscal year 1996 budget to support preliminary planning, engineering, schedule and cost studies.

- Endorse the open and deliberative process for further inquiry propased by Congressman Dellums for proceeding to a Key Decision Orie Prime prior to Key Decision Two.

- Announce that Lawrence Livermore National Laboratory is the Department's !referred site for the National Ignition Facility. 


\section{Appendix $\mathbf{H}$}

\section{Approval of Baseline Change Action March 1997}




\section{Department of Energy \\ Washington, DC 20585 \\ December 20, 1996}

MEMORANDUM FOR THE SECRETARY

THROUGH:

CHARLES B. CURTIS DEPUTY SECRETARY

THROUGH:

DONALD W. PEARMAN, JR.

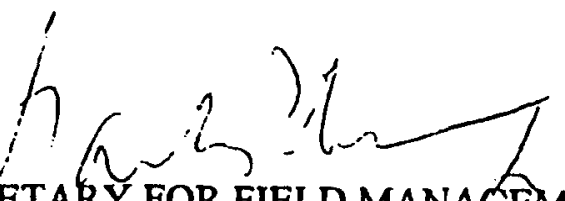
ASSOCIATE DEPUTY SECRETARY FOR FIELD MANAGEMENT

FROM:

Victor H. Reis $i$

Assistant Secretary for Defense Programs

SUBJECT:

ACTION: ACQUISITION EXECUTIVE APPROVAL OF BASELINE CHANGE PROPOSAL FOR THE NATIONAL IGNITION FACILITY

ISSUE:

Acquisition Executive approval is requested to adjust the cost and schedule baseline for the National Ignition Facility strategic system. If you approve the attached baseline change proposal, total project cost would be increased by $\$ 125.3$. million from $\$ 1,073.6$ million to $\$ 1,198.9$ million, the total estimated cost of construction would be increased by $\$ 203.1$ million from $\$ 842.6$ million to $\$ 1,045.7$ million, and the completion date would be extended by twelve months.

BACKGROUND: The National Ignition Facility (NIF) is a key element of Defense Programs' science-based Stockpile Stewardship and Management Program. This strategic system provides for design, construction and acceptance of a high-energy, high-power solid-state laser and target system for laboratory-scale weapons physics experiments, inertial confinement fusion ignition and research, and applications of high energy density physics. Preliminary design is complete and final design has started. The Record of Decision for the Stockpile Stewardship and Management Programmatic Environmental Impact Statement was issued on December 19, 1996 and the Lawrence Livermore National Laboratory, Livermore, CA has been selected as the construction site. The proposed cost and schedule baseline changes have been recommended for approval to the Assistant Secretary of Defense Programs by the NIF Level 1 DOE Headquarters, Baseline Change Control Board. These changes extend the baseline completion date by 12 months (or 20\%) from the end of FYO2 to the end of $\mathrm{FYO3}$, with an increase in the total project cost of $\$ 125.3$ million (or $11.7 \%$ ) from $\$ 1,0736$ million to $\$ 1,198.9$ million. The total estimated cost of 
construction increased by $\$ 203.1$ million from $\$ 842.6$ to $\$ 1,045.7$ million. However, other project costs decreased by $\$ 77.8$ million, thus limiting the increase in the total project cost to $\$ 125.3$ million.

DISCUSSION:

The proposed baseline cost and schedule increases are a result of: (1) the changes to the project scope (described below) incorporated in the preliminary design (Title 1); (2) the expected annual funding availability in the five year period FY 1998-2002; and, (3) selection of the Lawrence Livermore National Laboratory as the NIF construction site

The scope changes are:

- Facility user design requirements from the weapons program, weapons effects testing, and inertial fusion program needed to meet their programmatic missions.

- Site-specific infrastructure requirements for the Livermore construction site which were footnoted in the FY96 and FY97 Project Data Sheets.

- Title 1 design changes to meet operational and maintenance goals.

The changes to the total project cost associated with these scope changes is $\$ 74.3 \mathrm{M}$.

The remainder of the increase. $\$ 51 \mathrm{M}$, is attributable to the extension of the baseline completion date by twelve months to Oct 2003. This was necessary to conform the project's annual funding requirements to expected DP funding availability during the five year period.

The NIF is a significant step beyond the state of the art in inertial confinement science, technology and facility size. The project has been well managed and progressed on schedule: Title I design has been completed and LLNL has been selected as the site. The baseline scope changes are to accommodate requests by the user community. These scope changes and normal maturation of the project drive the cost increase. The cost increase is not unreasonable and reflects a wellestablished science base and conceptual design. An Independent Cost Estimate (ICE) conducted by the Office of Field Management has validated the scope. The cost increase which resulted from the extension of the baseline schedule has not been examined by the ICE. 
SENSITIVITIES:

POLICY IMPACT.

RECOMMENDATION: That you approve the recommended Baseline Change Proposal to

-Increase the baseline total estimated cost of construction by $\$ 203.1$ million from $\$ 842.6$ million to $\$ 1,045.7$ million

-Increase the baseline total project cost by $\$ 125.3$ million from $\$ 1,073.6$ million to $\$ 1,198.9$ million.

-Extend the baseline project completion date by twelve months from October 2002 to October 2003.

Attachment

APPROVE:

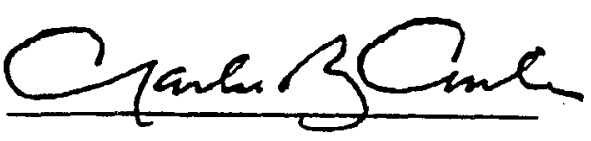

DISAPPROVE:

DATE:

March 7, 1997

Concurrences: General Counsel/Shebek for Nordhaus 1/13/97

Policy/Chupka 1/12/97

Economic Impact/Moody 1/8/97

Human Resources/Tamura for Durham 1/6/97

Chief Financial Officer/Smedley $1 / 13 / 97$

Environment, Safety and Health/Brush for O'Toole 1/14/97

Environmental Management/Alm (undated)

National Security/Baker 1/17/97

Congressional/Alcock for Forrister 12/27/96 


\section{Appendix I}

Critical Decision 3 Approval memorandum, March 1997 
Department of Energy
Washinglon, DC 20585

February 6, 1997
NIF-0002078

WBS 1.1.1.1

$1997-003291$

\section{MEMORANDUM FOR THE ACTING SECRETARY}

THROUGH:

FROM:

SUBJECT:

ISSUE:

\section{BACKGROUND:}

Charles B. Curtis

Deputy Secretary

Victor H. Reis UAt '

Assistant Secretary for Defense Programs

ACTION: Memorandum to the Energy Systems Acquisition Advisory Board Acquisition Exccutive requesting approval of Critical Decision 3 (CD-3), Start of Construction for the National Ignition Facility (NIF).

The Department's project management system process and.OMB Circular A-109, require that the Secretary, as the Acquisition Executive. approve CD-3, before the NIF can proceed to its next phase, the start of construction. It is critical that CD-3 is approved before March to prevent costly slippage in schedule.

The National Ignition Facility is a key element of Defense Programs' science-based Stockpile Stewardship and Management Program. This Strategic System provides for design, construction and acceptance of a high-energy, high-power solid-state laser and target system for laboratory-scale weapons physics experiments, inertial confinement fusion ignition and research, and applications of high energy density physics.

All prerequisite Critical Decision milestones, previously called Key Decisions (KDs), have been approved. These include $\mathrm{KD}-0$ (now $\mathrm{CD}$ 1). Approval of Mission Need (Reference 1), approved by Secretary Watkins on January 15, 1993; KD-1 (now CD-2), Approval of New Start (Reference 2), approved by Secretary O'Leary on October 20, 1994; and. KD-1' (prime) (Reference 3), an added decision milestone, approved by Secretary O'Leary on December 20, 1995. Approval of KD-1' was based on the finding that the technical proliferation concerns at the NIF were manageable and, therefore, could be made acceptable, and the NIF could contribute positively to U.S. arms control and nonproliferation policy goals. The Secretary delegated authority to approve the Project Execution Plan to the Assistant Secretary on June 14, 1996 (Reference 4). The Mission Need was reconfirmed at each successive milestone. 
The Record of Decision for the Stockpile Stewardship and Management Programmatic Environmental Impact Statement (Reference 5) was issued by Secretary O'Leary on December 19, 1996. Lawrence Livermore National Laboratory has been selected as the construction site. The Preliminary Safety Analysis Report (Reference 6) categorizes the NIF as a low hazard, radiological facility. DOE-OAK approved this report on October 3. 1996, in the Safety Evaluation Report on the Lawrence Livermore National Laboratory.

The NIF project has completed preliminary design (Title I) which added project scope changes to the conceptual design completed in May, 1994. These changes included: (1) facility user requirements from the weapons physics, the radiation effects testing, and the inertial fusion programs; (2) site-specific infrastructure requirements (previously only footnoted in the Project Data Sheet pending site selection); and. (3) design requirements to meet operational and maintenance goals. An independent design review committee conducted a detailed technical assessment of the preliminary design and in their Summary Report of December 9, 1996. (Reference 7), recommended proceeding with detailed engineering design (Title II), major long-lead procurement and site preparation. The NIF preliminary design formed the basis for DOE Field Management's Independent Cost Estimate (Reference 8) which was within 1 percent of the project's estimate. This constitutes excellent agreement and validates the NIF cost baseline for proceeding with final design. Final design and planning for the start of construction are proceeding in accordance with approved fiscal year 1997 plans.

Congressional funding for the NIF project in fiscal years 1996 and 1997 provided the Department's full requests. The 1997 appropriation included funding for site preparation and carly construction planning. The Department's fiscal year 1998 budget submission, including the NIF Project Data Sheet, requests full appropriation for the remaining funds necessary to complete construction of the NIF. The Project Data Sheet incorporates the scope changes discussed above and associated cost and schedule changes. These changes: (1) extend the baseline completion date by one year from the end of fiscal year 2002 to the end of fiscal year 2003; (2) increase the Total Project Cost from \$1,073.6 million to $\$ 1,198.9$ million, an increase of $\$ 125.3$ million; and, (3) are consistent in timing with overall program needs and capability and with anticipated obligational authority targets for Defense Programs for fiscal year 1998 and beyond. These scope, cost and schedule baseline changes were approved through the Level 1 NIF Baseline Change Control Board and subsequently concurred with by the Energy Systems Acquisition Advisory Board members, as a Level 0 action (Reference 9), on January 16, 1997. Final approval by the Acquisition Executive has been requested. 
SENSITIVITIES:

As of 2/19/97: On February 14, 1997. a lawsuit was filed naming DOE and the National Academy of Sciences (NAS) as defendants. The suit seeks among other things, to enjoin DOE from relying on a National Academy of Sciences Inertial Confinement Fusion technical review panel in making its decision to start construction (CD-3) beceuse, it alleges, DOE is in violation of the Federal Advisory Committee Act (FACA). While the NAS final report is expected in early March, DP has reached its technical conclusions without the NAS panel report. The Office of General Counsel concurs with DP and has no legal objection to DP's intention to proceed with CD-3.

POLICY IMPACT: $\quad$ Action is consistent with current Department policy.

RECOMMENDATION: Approve Critical Decision 3, Start of Construction for the NIF.

APPROVE:
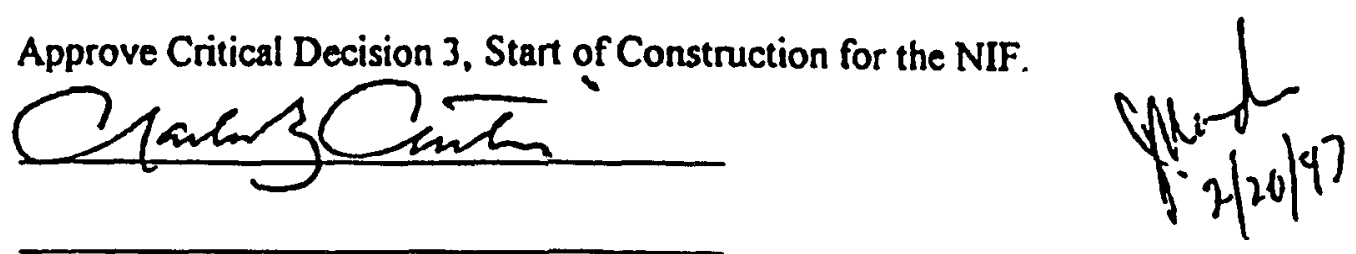

DATE:

March 7, 1997

The Energy Systems Acquisition Advisory Board Secretariat, Field Management, has received concurrences from all members of the Board.

Policy/Chupka Undated

Economic Impact/Moody 2/4/97

Human Resources/Tamura for Durham 2/21/97

Chief Financial Officer/Smedley 2/21/97

Environment, Safety and Health/Brush for O'Toole 2/24/97

Environmental Management/Alm Undated

National Security/Baker 2/21/97

Congressional/Forrister Undated

General Counsel/Johnston 2/19/97

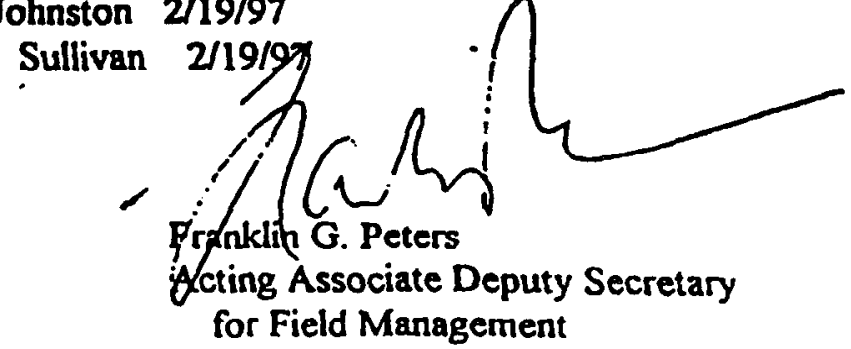




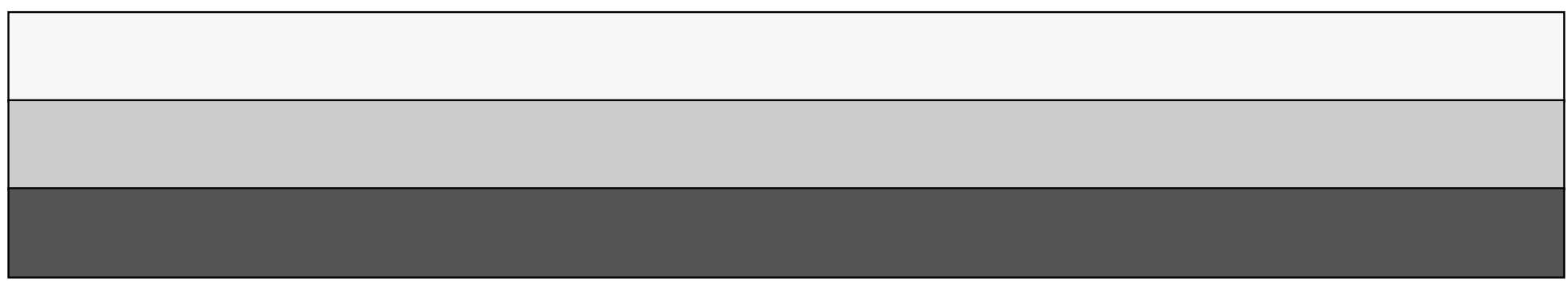

